\title{
Early Warning System for Economic and Financial Risks in Kazakhstan
}

\author{
Biswa Bhattacharyay \\ Dennis Dlugosch \\ Benedikt Kolb \\ Kajal Lahiri \\ Irshat Mukhametov \\ Gernot Nerb
}

CESIFO WORKING PAPER NO. 2832

CATEgORY 7: MONETARy POLICY AND INTERNATIONAL FinanCE

OCTOBER 2009

\footnotetext{
An electronic version of the paper may be downloaded

- from the SSRN website: Www.SSRN.com

- from the RePEc website: $\quad$ www.RePEc.org

- from the CESifo website: www.CESifo-group.org/wp
} 


\title{
Early Warning System for Economic and Financial Risks in Kazakhstan
}

\begin{abstract}
This paper proposes a macro-prudential financial soundness analysis that can be used by most developing and transformation countries with or without crisis experience as well as by developed countries with limited data. The objective is to detect economic and financial sector vulnerability, design appropriate remedial policy responses and undertake preventing actions to address vulnerabilities. The paper also discusses a process for identifying and compiling a set of leading macro-prudential indicators. The system will be tested using a case study referring to Kazakhstan.

The main novelty of the study lies in designing composite indicators for the real economy, the banking sector, the overall financial sector and finally the international economic environment of Kazakhstan and in studying the interaction of these composite indicators. An additional innovation is the relatively extensive use of qualitative business survey data to monitor vulnerability or crises; these surveys are data which until now have not been used much in this area of research.
\end{abstract}

JEL Code: F30, E58, E44, G20, G10, G32, G28.

Keywords: banking crisis, leading indicators, Kazakhstan.

$$
\begin{gathered}
\text { Biswa Bhattacharyay } \\
\text { Asian Development Bank Institute } \\
\text { Japan - Tokyo 100-6008 } \\
\text { bbhattacharyay@adbi.org } \\
\text { Kniversity at Albany, } \\
\text { USA - A } \\
\text { klahir } \\
\text { National Analytical Centre under the } \\
\text { Government and National Bank of } \\
\text { Kazakhstan, National Bank } \\
\text { Kazakhstan - Almaty, 050040 } \\
\text { imukhametov@nac.gov.kz }
\end{gathered}
$$

\author{
Dennis Dlugosch \& \\ Benedikt Kolb \\ Ifo Institute for Economic Research at the \\ University of Munich \\ Germany - 81679 Munich
}

\author{
Kajal Lahiri \\ University at Albany, State University of New York \\ USA - Albany, NY 12222 \\ klahiri@albany.edu \\ Gernot Nerb \\ Ifo Institute for Economic Research at the \\ University of Munich \\ Poschingerstrasse 5 \\ Germany - 81679 Munich \\ nerb.ifo.de
}

The paper was produced in the context of an early warning project conducted in collaboration with the National Analytical Centre of the Government and the National Bank of the Republic of Kazakhstan and supported by the German VW Foundation. 


\section{Table of Contents}

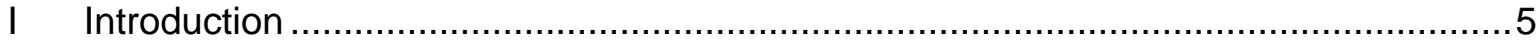

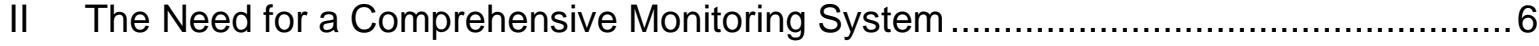

II.1 Financial Vulnerability and Causes ……………..................................

II.1.1 Proposed Vulnerability Detection and a Remedial Policy Formulation System 8

II.1.2 Designing a Reference Cycle for Banking and Financial Crises ....................11

II.2 Identification and Compilation of an Appropriate Set of Macro-Prudential/

Financial Soundness Indicators.......................................................................... 11

III Macro-Prudential Indicators: Analysis and Interpretation of MPIs ............................14

III.1.1 Trend Analysis (Indicator Approach) …….........................................15

III.1.2 Early Warning Signal (EWS) Models .............................................15

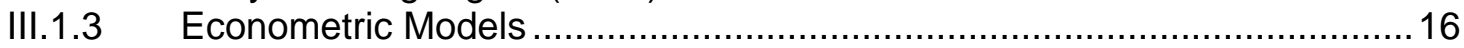

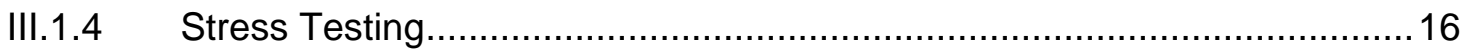

IV A System of MPIs in Form of Composite Indicators for Kazakhstan .....................17

IV.1.1 Four blocs to distinguish in our analysis .............................................18

IV.2 How to Construct the Four Composite Indicators.........................................18

IV.2.1 Composite Leading Indicator for the Real Economy (CLI) ......................19

IV.2.2 Composite Coincident Indicator for the Real Economy (CCI) ..................22

IV.2.3 Composite Banking Stress Indicator (CBI) ……...................................24

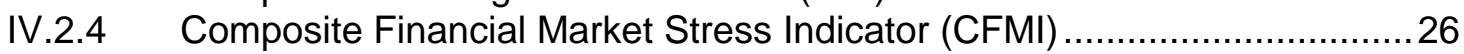

IV.2.5 Indicator for the International Economic Environment of Kazakhstan (IEEK) 29

IV.3 Analyzing Current and Future Trends - the Interaction of the Composite

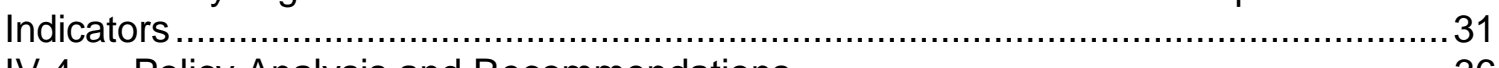

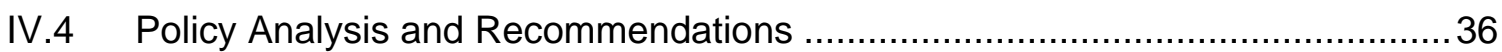

V Concluding Remarks.....................................................................................

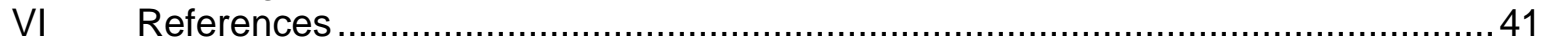

VII Appendix: Technical Details / Sources for the Construction of the Indicators .........44

VII.1.1 Composite Leading Indicator (CLI) ……….................................... 44

VII.1.2 Composite Coincident Indicator (CCl) ……...................................... 45

VII.1.3 Composite Financial Market Risk Indicator (CFMI) ……........................45

VII.1.4 Composite Banking Stress Indicator (CBI) ……..................................46

VII.1.5 International Economic Environment Indicator (IEEK) ……....................46 


\section{Table of Figures}

Figure 1: A Quantitative System of Macro-Prudential Analysis and Remedial Policy Formulation for High-Frequency Monitoring of Vulnerability ............................ 10

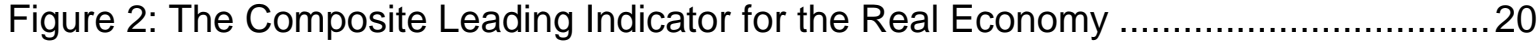

Figure 3: The Composite Coincident Indicator for the Real Economy ..........................23

Figure 4: The Composite Banking Indicator ........................................................... 24

Figure 5: The Composite Financial Market Indicator ............................................ 27

Figure 6: The Composite Financial Market Indicator without the (CA/GDP)-Indicator .......27

Figure 7: The CFMI without the inverted Real Exchange Rate (CFMI-IRER) and the IRER Indicator itself (IRERI), both against the CBI shifted 15 months backwards (all

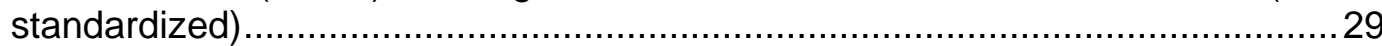

Figure 8: The International Economic Environment Indicator .................................... 30

Figure 9: Comparison of the Composite Leading Indicator and the Composite Coincident Indicator (both standardized) .................................................................... 31

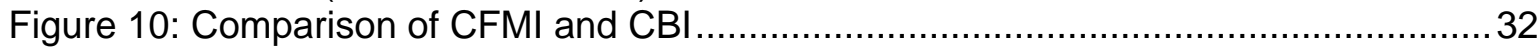

Figure 11: Comparison of CFMI and CBI (both standardized) ................................... 33

Figure 12: Prognosis of the CBI by a regression on the CFMI shifted by 15 months ........34

Figure 13: The IEEK compared to CLI and CCI (all standardized) ................................35

Figure 14: The IEEK compared to the Kazakh WES Indicator (WESI) - both standardized 


\section{Introduction}

Over the last decade, many developing and transformation countries have become increasingly integrated into global financial markets through deregulation, liberalization of the capital account and privatization of the market. Several emerging market economies witnessed a large number of financial crises since the 1980ies which resulted in severe economic, social and political problems. The devastating impact of the 1982 and 1994-95 Mexican crises, the 1997-98 Asian financial crisis and the 1998 Russian crisis suggest that maintaining financial sector stability by reducing vulnerability is highly crucial.

However, financial crises were not limited to developing and transformation countries only. During the last decade, several industrial countries witnessed financial crises that had and still have significant macroeconomic consequences; examples are some countries in Europe (European currency crisis in 1992-93), Japan in the 90ies, some of the Nordic countries in the early 90ies and of course the current economic crisis which emerged in the financial centers of the Western economies.

In order to reduce vulnerability to crises, countries should have sound economic policies, a flexible exchange rate, effective institutions, good governance, particularly well supervised financial markets and an appropriate monitoring system for vulnerability which might possibly lead to crises.

As financial sectors are highly vulnerable to instability and systemic risk, monitoring these sectors as well as spillover effects of weaknesses of the real sector assumes great importance, considering the severity and frequency of financial crises, especially of combined currency and banking crises such as witnessed in the recent past. The main question that arises is what can be done to reduce the damage of these events. Is it possible to maintain a moderate degree of stability in the financial markets of a region with liberalized capital flows? In any case, there is a need for an increased effort in reducing vulnerability to crises. Therefore, an appropriate and effective system for early vulnerability detection and remedial policy formulation is clearly vital for reducing such vulnerability.

Some progress has been made in identifying and compiling accurate and timely crisismonitoring indicators. The focus has now shifted towards the development of techniques for the proper analysis and interpretation of data, since no universally accepted standard or system of macro-prudential analysis exists. Many countries and especially crisisaffected ones are now analyzing crisis-monitoring, so-called macro-prudential or financial soundness indicators (MPIs or FSIs). However, this analysis usually does not lead to remedial policy formulation and actions. There seems to be a disconnection between the analysis of MPIs and the formulation of an effective political remedy.

This paper proposes a macro-prudential or financial soundness analysis and a remedial policy formulation system that can be used by most developing and transformation countries with or without crisis experience, as well as by developed countries with limited data. The main purpose is to detect economic and financial sector vulnerability, design appropriate policy responses and undertake preventing actions to address vulnerabilities. The proposed system outlines a process for identifying and compiling a set of leading MPIs, and methods for macro-prudential analysis and a process for formulating remedial policy actions for addressing vulnerability. It focuses on high frequency monitoring of financial sector vulnerability and spillover effects from weaknesses in the real sector for 
early detection of irregularities and swift remedial policy actions. Furthermore, an empirical illustration of the system using Kazakh data is presented.

\section{The Need for a Comprehensive Monitoring System}

The cost of a financial crisis could be severe in terms of reserve losses, output decline and poverty. Usually, governments and thus taxpayers incur huge fiscal cost by any standard. Costs measured by output losses are comparatively smaller but still large. Financial sector vulnerability affects the macro economy through several channels, such as credit crunch, high interest spreads, low financial intermediation, lending caution, disruption of the payments system and a general loss of confidence. It also affects the effectiveness of monetary policy due to low monetarization, volatility in monetary aggregates, rates irresponsive to open market operations, stickiness in interest rates, and a high number of non-performing loans.

According to a paper on the Copenhagen Consensus, ${ }^{1}$ Eichengreen (2004) states: "The loss from the average or typical financial crisis is around 9\% of GDP (see Bordo et. al., 2001 for details), and the severe crises, such as those of Argentina and Indonesia, caused output or GDP to fall over 20\%, an economic loss higher than those incurred due to the Great Depression. According to Chen and Ravallion (2001), the 1997 Asian financial crisis increased the number of people below poverty line in the region by 22 million. Even though one can question the accuracy of such estimates, the avoidance of such crises could benefit emerging-market economies by $\$ 107$ billion a year".

In 1997 and 1998, sudden outflows of capital from several East Asian countries, such as Indonesia, the Republic of Korea, Malaysia, the Philippines and Thailand, reeled from a devastating financial crisis, which led to severe economic, social and political problems. Their open financial markets sparked a plunge in their currencies, stocks and other assets and harshly damaged some of their financial institutions. Economies contracted and millions of people saw their standards of living worsening. Economic development was set back for years in some areas. The Asian financial crisis has demonstrated how financial integration can expose developing countries to external shocks. These shocks reversed the success in poverty reduction gained by openness of the financial markets in some countries and caused a significant increase in poverty in the short and medium term. Following years of robust growth, of strides in standards of living and export expansion, these economies suffered from a crippling devaluation, massive capital flight, corporate and banking failures and spikes in unemployment. In a relatively short span of time, close to US\$ 100 billion of capital flew out of the region.

During the Peso crisis of 1995, Mexico witnessed its worst recession in 60 years. The real GDP declined by 6\% (Goldstein et. al., 2000). According to a study by Baldacci et al. (2002), the 1994/95 Mexican financial crisis gave rise to an increase in poverty and income inequality. The incidence of poverty as defined poverty head count ratio increased by around 6\% to reach $17 \%$ in 1996 from $10.6 \%$ in 1994, reversing the reduction in poverty made between 1992 and 1994.

But even for developed countries, financial crises can have devastating effects. During the Exchange Rate Mechanism Crisis (ERM) of 1992-93, European countries lost $\$ 150$ billion

\footnotetext{
${ }^{1}$ Paper written on the Copenhagen Consensus and presented at Copenhagen on 25-28 May 2004.
} 
to $\$ 200$ billion of reserves, when an unsuccessful official exchange market intervention was undertaken to control the devaluation and/or floating of ERM currencies.

The current financial crisis which had its origin in the USA (more exactly, in the sub-prime sector there) has been spreading almost all over Europe, Asia, Australia and other parts of the world and has gone far above the mortgage sector. It is too early to make estimations of the costs of this crisis both in the private and in the public sector, but in any thinkable scenario these costs will reach a new dimension in crisis-related expenditure.

It is in this context that the monitoring of both the financial sector and spillover effects from weaknesses in the real sector assumes great importance. The monitoring system should be able to detect the magnitude and nature of economic and financial vulnerability at an early stage and suggest appropriate policy actions to address them in order to prevent a financial or currency crisis. Also, the virulence of the contagion among neighboring countries during the crisis highlighted the need for a regional surveillance mechanism, particularly a peer review process to prevent future crises and financial instability or to minimize their impacts in the region.

\section{II.1 Financial Vulnerability and Causes}

The financial vulnerability is a complex and dynamic concept, and therefore it is difficult to explain. At present, there is no universally accepted definition of financial vulnerability (Osterelo and De Haan, 2003). Following the definition of financial stability by Houben et al. (2004), financial vulnerability can be defined as a situation in which the financial system cannot allocate resources efficiently between activities and across time and cannot assess and manage financial risk and thus weakens economic performance and wealth accumulation. At the same time, it is not capable of absorbing shocks or vulnerability and thus cannot prevent an adverse impact. In general, it is easy to measure solvency of a financial institution, but very difficult to measure vulnerability of a financial system.

There are several causes of financial vulnerability. The major reasons include:

(i) fragility of the financial sector or system,

(ii) spillover effects of weaknesses of the real sector,

(iii) weaknesses in governance of financial institutions and their supervising authorities and risk management,

(iv) macroeconomic policy mismatch,

(v) contagion effect,

(vi) weakness in international financial system or markets,

(vii) sudden financial liberalization and

(viii) weakness in legal infrastructure.

Ideally, all such possible causes should be monitored. This paper, however, will focus on monitoring the vulnerability of the financial sector and spillover effects from weaknesses in the real sector.

Contagion is a concept which is also difficult to define. It can be explained as the transmission of a financial crisis to a country as a result of its real and financial interdependence with other countries that are already witnessing a financial crisis (Fratzscher, 2002). On many occasions these financial crises did not only occur in a single 
country, but had a contagion effect to other regional countries as well. For example, the Latin American crisis of 1994 and the Asian crisis of 1997 affected many countries in the respective regions and sometimes across countries. For example, after July 2, 1997, following the devaluations of Thailand's currency, those of Malaysia, Indonesia, the Philippines and later Singapore rapidly weakened. This so-called Asian crisis also adversely affected several non-Asian developing and transformation countries including Russia and Brazil due to a (mis-)perception of increased vulnerabilities in all emerging market economies.

The Asian crisis spawned a massive literature on the economics of crisis, in which numerous hypotheses have been advanced on the origin, development, and resolution of crises. There are, however, two main explanations for the crises like the Asian one. First generation models attribute the crisis to weak economic fundamentals such as unsustainable economic policies, vulnerability of the financial sector, and structural imbalances. This traces the crisis to inconsistency in policies such as monetization of persistently large budget deficits under a regime of fixed exchange rates (Krugman 1979). Second generation models, on the other hand, link the crisis to the arbitrary shifts in market sentiments and emphasize the role of panics and self-fulfilling expectations (Obstfeld, 1986, Pesenti and Tille 2000; Estanislao, Manzano, and Pasadilla 2000).

The general understanding is that the financial crisis in Asia was multifaceted including a capital account crisis. It caused currency and banking crises. As Pesenti and Tille (2000) emphasize, the fundamental imbalances stressed by first generation models make a country vulnerable to shifts in investor sentiment; thereafter, once the crisis has begun, the second generation models explain the spiral and self-fulfilling nature of speculations.

\section{II.1.1 Proposed Vulnerability Detection and a Remedial Policy Formulation System}

Monitoring can be carried out by different groups/sectors - markets, firms, consumers, policymakers, regional and international financial institutions, supervisory groupings, peer groups and countries with strong trade or economic links - with each level having differing approaches and objectives. However, to be effective, monitoring does not only have to be correct but it should be implemented properly and if possible by economists close to the actual developments in the country itself. Therefore, monitoring domestic markets and institutions as well as stability-oriented policy should be undertaken by the countries themselves and should not be left to multilateral organizations or regional and international financial institutions. Ideally, high frequency monitoring should be performed by a high level monitoring committee with representatives from central banks, the ministry of finance and other relevant ministries and supervisory authorities.

The proposed system outlines a process for identifying and compiling a set of leading MPIs, and methods for macro-prudential analysis that will serve as flexible tools for analyzing and interpreting fluctuations in MPIs and translating underlying information about the magnitude and nature of vulnerability (or strength) and remedial policy implications for addressing vulnerability. The system involves the following steps:

1. Identification and compilation of leading indicators to represent key sectors of the domestic economy, such as money, credit and interest rates, banking, public finance, external debt and international flows, trade and international reserves, stock market 
and business tendency surveys for the corporate sector (some indicators for external sectors or the global economy, maybe represented by the major trading partners of the country in question, could also be included)

2. Construction of composite indicators to condense the information contained in the multitude of individual indicators and study of the interaction of the different composite indicators

3. Use of a signaling method for vulnerability assessment and

4. Policy analysis for remedial policy recommendations to address vulnerabilities.

This system will serve as a basis for any preventive and remedial measures to address detected weaknesses in the economy and the financial system. A graphic representation of the framework is shown in Figure 1. Each of the above steps is explained in detail. 
Figure 1: A Quantitative System of Macro-Prudential Analysis and Remedial Policy Formulation for High-Frequency Monitoring of Vulnerability
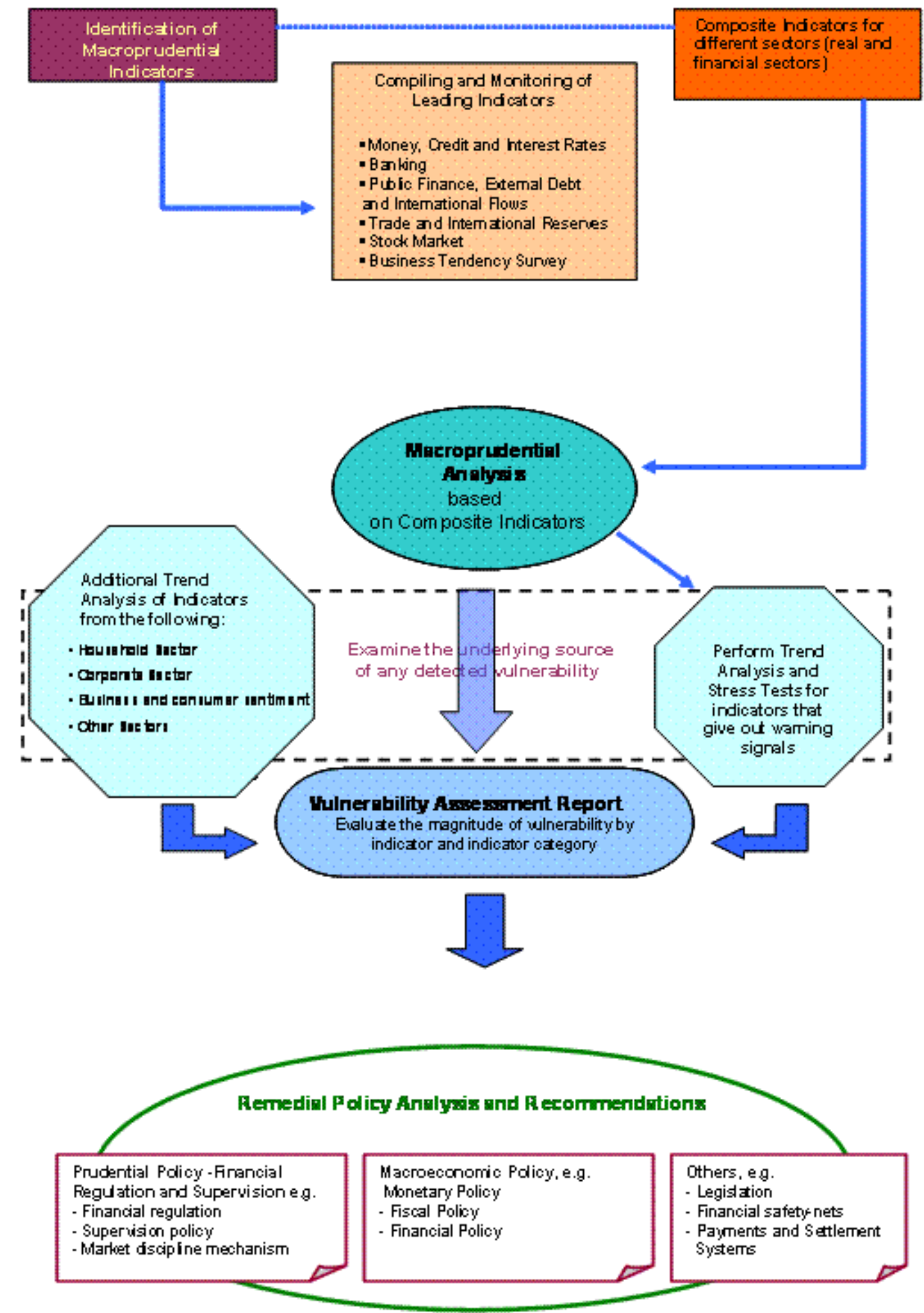


\section{II.1.2 Designing a Reference Cycle for Banking and Financial Crises}

It is relatively easy to measure the performance of a composite leading indicator predicting the real economy. Much more difficult is to pinpoint the timing of bank crises which are in the focus of the current study. In the literature two approaches have been discussed. The first approach is - like in the case of indicators for the real economy - based on quantitative analyses of high frequency data (mainly monthly data); the other approach is based on characteristic crisis events. In this paper we follow the event-based approach. According to Demirgüc-Kunt and Detragiache (1998) a banking crisis can be identified if at least one of the following conditions holds:

(i) The ratio of non-performing assets to total assets in the banking sector exceeds ten percent;

(ii) The cost of the rescue operation was at least two percent of GDP and

(iii) Banking sector problems resulted in a large-scale nationalization of banks.

In a similar way Caprio and Klingebiel $(1996,2003)$ as well as Lindgren, Garcia and Saal defined a banking crisis. In our paper we follow a proposal by $\mathrm{V}$. Vallez and $\mathrm{C}$. Weisstroffer (Deutsche Bank Research 2008); we consider events that qualify either as a banking sector distress or as a systematic crisis according to the following criteria:

(i) Banking sector distress is indicated by the failure of a number of institutions within a short interval, or the failure of a single institution of systemic relevance. Even in the absence of failures, an episode qualifies as banking sector distress if policy and regulatory actions to overcome strains in the banking sector are taken. Such actions may be revealed by (de facto) forced takeovers or mergers, or by the extension of public assistance (financial or otherwise) to the banking sector.

(ii) An episode evolves into a systematic crisis if most or all of the system's bank capital is depleted. Widespread bank runs, large-scale failure of banks, or massive public intervention to avoid systemic breakdown will be regarded as indications of a systemic crisis.

On the basis of such a broad definition we can consider the period from mid 1998 to autumn 1999 and autumn 2007 till today as periods where the banking sector in Kazakhstan has experienced distress, given the fact that the state had to step in as lastresort equity provider in both cases in order to avoid a breakdown respective a closure of important banks. Moreover, in both cases the national currency was devalued. As a rule, it is not possible to date the beginning or the end of a banking crisis exactly on a specific month.

Thus, for assessing whether the composite leading indicators gave advance warning, the reference dates for the beginning of a banking crisis would be autumn 1998 and autumn 2007, but due to the shortage of important components of the composite indicators, only the 2007-2009 banking crisis can be evaluated. This will be done in chapter III.

\section{II.2 Identification and Compilation of an Appropriate Set of Macro- Prudential/ Financial Soundness Indicators}

The availability of accurate and timely information is very important as demonstrated particularly by the 1997/98 financial crisis in Asia, which highlighted the informational gaps 
in the affected economies. To illustrate, the build-up of currency and maturity mismatches, which had been the core of the weakness of many financial systems in Asia, was masked initially by high economic growth rates, manageable inflation, and heady capital inflows. This lack of transparency contributed to the vulnerability because in a world of global capital flows, crises can arise if information surprises cause market participants to change their expectations suddenly and sharply. Lack of data and weak rules of disclosure may hinder any effort to undertake economic and financial monitoring during a crisis, as it happened in Asia in 1997/98. In contrast, transparency and a continual flow of market information can help to avoid panics and "creditor-grab" behavior.

In recent years, particularly following the Asian crisis, several studies have been published proposing crisis-monitoring indicators or early warning indicators that could be used to monitor the vulnerability of an economy. Bhattacharyay (2004) reviewed developments in the identification, compilation, analysis and interpretation of MPIs/FSIs. For many developing and transformation countries, it is quite difficult to estimate the crisis monitoring indicators due to a lack of timely and appropriate data. The majority of official statistics is available with considerable time lag and not very useful in estimating early warning indicators.

Compilation and analysis of MPIs are important components of economic and financial sector monitoring activity. MPIs are a broad set of indicators that reflect the vulnerability of the financial and real economic systems to shocks. MPIs include macroeconomic indicators, such as inflation, asset prices, and arrears in the economy, as well as aggregated micro-prudential indicators, such as capital adequacy, asset quality, commodity price risk, and sovereign yield spread.

The development of MPIs is rather recent. The tools that are utilized to quantify and qualify the soundness and vulnerabilities of the financial system are varied and can potentially be made as complex or sophisticated as needed. Macro-prudential analysis is a technique that uses information from MPIs to assess and monitor the strength or vulnerability of financial systems. The operation of a monitoring system demands resources and technical expertise depending on its complexity. The more sophisticated the system, the more costly it is to monitor and conduct macro-prudential analysis. MPIs encompass FSIs and other relevant information that can provide a broad picture of a country's economic and financial condition such as the status of the institutional and regulatory frameworks or compliance with international standards (Sundararajan et al., 2002). FSIs are a special subset of MPIs which specifically monitor the health and soundness of financial institutions and markets and their corporate and household counterparts.

The effectiveness of the monitoring system should be evaluated according to the purpose for which it is designed. For instance, MPI analysis should be evaluated on how well it can track the vulnerability of a financial system and whether it can effectively disseminate information to economic agents in the pursuit of better disclosure. Early warning systems can be evaluated on their record in predicting a crisis. Despite the increasing interest in more complex techniques employed in deploying monitoring and early warning systems (see Berg and Patillo 1999b for a review), it should be borne in mind that there are at least two aspects in monitoring: technical identification and interpretation of the indicators. It is thus important not only to define the purposes to which the indicators are to be used but also the analytical framework within which they are to be interpreted. 
Because financial and currency crises are complex phenomena, the identified set of MPIs should be comprehensive in nature. In this light, the MPIs must not be limited only to banking and financial statistics but have to take into account the general macro-economy as well as the corporate and household sectors. In such a manner, a more comprehensive assessment of the condition and health of the economy and financial systems can be conducted. At the same time the identification of MPIs should be a dynamic process depending on the emerging vulnerability in certain sectors of the economy, such as emerging vulnerability in the insurance sector or credit-card and consumer-loans business sector.

Maintaining a wide set of indicators has a downside - collecting and monitoring a multiplicity of variables can be a daunting task, and can ultimately entail large costs. However, these costs can be reduced if it is possible to identify a manageable subset of core indicators which can effectively give signals of vulnerability to crisis. To illustrate, one of the criteria for choosing a core set of variables is whether the indicators are leading or coincident. Identifying a core set of indicators is not an easy task and work in this area, e.g. the IMF system of MPIs is still considered as work in progress. For work on MPIs to be fruitful, it has to be harmonious with the existing monitoring system of the country, taking into account the data constraints faced by the country in question. Different structures, levels of economic development and degrees of financial sophistication imply that different sets of MPIs are relevant to specific countries.

Ideally, the set of monitoring indicators should include FSIs giving an appropriate image in terms of liquidity, credit, market risks and banking health/soundness as well as of other MPIs on macroeconomic vulnerability which may have spillover effect on the financial sector. As experience in business cycle research shows, the nature of business cycles can change from one cycle to the other. Whereas one time the downturn may start from restrictive monetary policy, the next time the main culprit for the downturn may lie in a sudden weakness of important export markets or in a cost push caused by a sharp increase of oil and/or other commodity prices. For all these reasons, composite leading and coincident indicators proved to be the most appropriate tools to cover different facets of factors shaping the business cycle, without getting lost by hundreds of individual time series. Similarly, in analyzing and forecasting financial crises, properly designed composite indicators may facilitate the analytical work without getting stuck in a multitude of signals from many individual and sometimes diverging indicators.

The International Monetary Fund (IMF) has been actively involved in the development of MPIs/FSIs. IMF (2001a) proposed a broad array of MPIs that could give a comprehensive assessment of the financial system and subsequently a core set of FSIs that are more useful and convenient for periodic monitoring (Sundararajan et al., 2002). These aggregated MPIs mainly adopt the CAMELS framework, which consists of six groups of indicators reflecting the health of financial institutions: capital adequacy, asset quality, management soundness, earnings, liquidity, and sensitivity to market risk. Final sets of IMF core and encourage indicators are available in the "Compilation Guide on FSI" (2004) which provides guidance on the concepts and definitions, sources and techniques for their compilation and dissemination. Another example of collecting a set of crucial indicators to monitor the financial well-being of a country has been developed by Bhattacharyay and Nerb (2002) based on experience of the Asian Development Bank (ADB) during the Asian financial crisis in the late 90 s. 
One of the main objectives of choosing a core set of leading indicators is to identify indicators that contribute important information and therefore appear to be particularly promising for financial and economic monitoring. Although a broad and exhaustive set of indicators could potentially give a more complete assessment, they can be costly to compile and unwieldy to maintain. For the purpose of periodic high frequency monitoring, a separate core set of MPIs of manageable size should be kept and updated regularly.

As indicated earlier, one criterion for inclusion into the core set of MPIs is early warning capacity. Hence, the MPI should be a leading indicator or, at the very least, a coincident one. An MPI is a leading indicator if it sends early vulnerability signals and coincident if it signals simultaneously with vulnerability. For a short-term monitoring system, however, only indicators that are available on a monthly or at least quarterly basis can be useful.

The selection of core indicators should be harmonious with the existing monitoring system of the country and take into account the data constraints. A country should adopt an appropriate core set of indicators chosen e.g. from the commonly agreed ones of the ADB, the FSIs by the IMF and other suitable indicators from crisis-related studies. The selected indicators should be tailor-made for a country's specific characteristics, based on economic rationale and early warning capability and available for high frequency monitoring. After having identified the most important indicators to describe the financial status of a country, intelligent forms to condense this information into few composite indicators have to be found in order to facilitate the analysis and to make such a monitoring system relevant also for policy makers.

\section{Macro-Prudential Indicators: Analysis and Interpretation of MPIs}

Some progress has been made in identifying and compiling accurate and timely MPIs. The focus is now beginning to shift towards developing techniques for the proper analysis and interpretation of data. Work on the analysis of MPIs and their interpretation is still recent and there is no consensus on the best analytic framework for determining the vulnerability of a financial system or a set of widely accepted MPIs. It should be noticed that the task of macro-prudential analysis or the framework for identifying, analyzing, and interpreting MPIs are still work in progress.

Various international and regional financial institutions such as the IMF, the Bank for International Settlements (BIS), ADB, European Central Bank (ECB) as well as private firms are still in the process of developing or testing different systems. In general, most macro-prudential analysis is based on trend analysis and the identification of large movements in the level of selected MPIs for assessing risk and vulnerability leading to a crisis. These methods usually analyze a composite of macroeconomic and microeconomic prudential indicators. Most macro-prudential analysis is judgmental together with other tools of macro-prudential assessment. As such, there is no standard system for macroprudential analysis at present. Yet, as the experience of the Asian crisis shows, a systematic monitoring of the financial and economic systems is an important element in crisis prevention strategies.

There are several studies based on empirical analysis of countries that have been affected by crises in the past. The identified indicators have been found useful to predict the past crises based on past time-series data. However, it is not sure whether the same indicators would be able to predict future crises with a reasonable degree of accuracy. At the same 
time, it is not possible to predict the point of time at which the crisis sets in. Another major problem in crisis-monitoring activities is erroneously predicting vulnerability that may cause a confidence problem in the market and thus initiate a crisis. Therefore, it is not clear if the use of quantitative models for predicting probabilities of a crisis is useful.

A further major obstacle is to come up with appropriate threshold values (benchmarks) signifying vulnerability for each indicator. When the level of an indicator is high, risk and vulnerability are large. However, there are no benchmarks on how large the magnitude of the indicator should be. No norms are available and there is an urgent need to develop benchmarks. Until these are available, macro-prudential analysis should not be limited to quantitative indicators alone. Qualitative information is very important, so that economists dealing with these indicators should keep in mind additional information which could complete the picture, like e.g. credit ratings by international credit rating agencies.

At present, most developing as well as developed countries conduct macro-prudential analysis based on the trends of available MPIs, on any large or significant movement away from these trends and on additional expert judgment. Any particular kind of risk, such as liquidity risk, has to be assessed by a set of related indicators, and proper judgment has to be used to detect any significant vulnerability.

There exist several methods how to use MPIs to monitor economic and financial vulnerability. The major methods include: (1) trend analysis, which detects vulnerability when there are major fluctuations in a particular indicator; (2) Early Warning Signal (EWS) models, which estimate the probability of a crisis occurring through quantitative or (3) econometric techniques and (4) stress-testing, which gauges vulnerability by estimating the impact of a range of future shocks to the system on certain variables. A country should adopt an appropriate framework tailor-made for its specific characteristics using all or some of the above methods for macro-prudential analysis. Brief explanations of these methods are presented in the following.

\section{III.1.1 Trend Analysis (Indicator Approach)}

Trend analysis implies looking at the movement of data over a given period of time and taking note of deviations from an observed pattern or large fluctuations. The major drawback of this technique lies in the interpretation of notable data deviation. It would not be immediately apparent whether this signifies stress in the system or simply a result of structural breaks, e.g. due to changes in regulations or regimes. As it is somewhat subjective, the reliability of trend analysis depends largely on the skill and experience of the technical staff. It is currently the most common method used because it is costeffective, transparent, and simple enough to be easily grasped by policymakers. In order to make trend analysis more effective, the construction of a few composite indicators plus a thorough analysis of the interaction of these summary indicators is proposed in this paper.

\section{III.1.2 Early Warning Signal (EWS) Models}

Signal Models can be regarded as a special form of trend analysis. The approach is more formalized than the general form of trend analysis described above. The models estimate the probability of a crisis occurring through quantitative or econometric techniques based on the movement of MPIs; it is a sound and objective method for early warning. 
Signal models are mainly used for the detection of looming currency crises, but they can also be applied for signaling a banking crisis or a recession in the real sector. Early warning models based on MPI are relatively new approaches introduced and discussed in academic and policy circles. Some of the more recent pieces of work in this area are Kaminsky and Reinhart (1999), Kaminsky, Lizondo, and Reinhart (1998), Goldstein, Kaminsky, and Reinhart (2000), Berg and Patillo (1999), Edison (2000) and Berg et al. (2004). The method is used as well in several private financial institutions like Goldman Sachs and Credit Suisse First Boston (Berg and Petillo 2004).

There are generally two types of EWS models, one that is based on a composition of leading indicators and another that makes use of probit/logit models. The composite indicator model creates a composite figure using the number of "warning signals" obtained from a set of MPIs and directly tying it with a probability of a crisis. A warning signal is emitted whenever an indicator theoretically associated with a crisis breaches a critical threshold (Kaminsky, Lizondo and Reinhart, 1998). Probit or logit models, on the other hand, compute a probability of the occurrence of a crisis based on changes in behavior of indicators prior to crises (Berg et al. 1999). There are separate EWS models for currency and banking crises. No common model is available for predicting all types of crisis.

The choice of approach in analyzing and interpreting MPIs depends on several factors, such as the desired level of accuracy, cost, timeliness, the purpose and nature of expected policy action and technical capacity of monitoring personnel and policy makers. Clearly, there are trade-offs among these factors. For instance, simple methods can generate indicators faster than more complicated ones, but they may only be adequate if the goal is simply to alert the authorities about possible vulnerabilities in the system. It may not be able to generate specific probabilities of the occurrence of crises that more sophisticated techniques can provide.

\section{III.1.3 Econometric Models}

A complete econometric model to simulate and forecast financial turbulences is not common. On the other hand, there are many examples where some partial aspects of a crisis are simulated, e.g. in the case of Kazakhstan sharp fluctuations of the oil price and its impact on GDP, exchange rates, inflation etc. These simulations are normally performed with the help of a VAR-model (see e.g. M. Gronwald and J. Mayr, 2009) or within a DSGE ("Dynamic Stochastic General Equilibrium") framework. Econometric models have the advantage of being objective and reproducible without any subjective bias. However, they often rely heavily on external assumptions and are not as flexible to handle as appears to be necessary in the case of a very complex topic as financial vulnerability.

\section{III.1.4 Stress Testing}

Stress testing is a multi-step simulation process or method of examining key risks, vulnerabilities and exposures in an economic or financial system. It is designed to evaluate vulnerability assuming major changes or shocks in the system. It provides information on the behavior of a system under exceptional but plausible shocks or the impact of a range of future shocks to certain variables of the system. It estimates changes in the MPI after one or more specific shocks that are based on historical or hypothetical (but plausible) circumstances, i.e., the impact of an economic slowdown on the level of nonperforming loans. Stress tests, however, do not estimate the probability of the occurrence of a shock. 
Stress testing is regularly used in the Financial Sector Assessment Program (FSAP) of the IMF/ World Bank (Sundararajan et al. 2002 and IMF and World Bank, 2003). IMF (2001b) provided further details on stress testing. Blascke et al. (2001) presents an overview of issues, methodologies and FSAP experience regarding stress tests.

The stress testing involves the following steps:

(i) Identifying major vulnerabilities, potential sources, exposure and risks of shocks, such as on variables like interest rate, exchange rate, credit, equity prices, liquidity, inter-bank contagion, real estate, key export, key commodities like oil - all in terms of a fall in prices and volatility;

(ii) Defining coverage and identifying data: all systemically relevant institutions and exposures;

(iii) Calibrating shocks and scenarios: establishing key linkages between the financial system and the real economy - a formal macroeconomic model or macrosimulation models

(iv) Selecting and implementing methodology-crunching numbers: translating the various outputs of the macroeconomic model into financial institutions' balancesheet and income statements

(v) Interpreting and using the results: policy makers compare the impact of a common set of shocks on different institutions. For interpreting stress tests, one should consider the limits and assumptions on which they are built (Jones et al., 2004, and Cihak, 2003)

Stress testing has some limitations. Like trend analysis, it relies on the judgment and experience of monitoring staff to identify the proper set of scenarios to be used in the test and to interpret the results correctly. The testing allows only for a first-order approximation of the true potential loss exposure. It does not capture the full range and interaction of risk exposure (such as operational and legal risk). It should be compared to other measures of risk exposure such as empirical analysis of macro-prudential/ financial soundness indicators. Moreover, it is complicated and time-consuming and hence difficult to be frequently undertaken, which makes it an inappropriate tool for high frequency monitoring. Furthermore it is a resource-intensive process in terms of technical expertise, data requirement and budget.

A fundamental issue to consider is whether crises are predictable, which, as the literature suggests, is still subject to qualifications. The choice of the model is also determined by the technical capacity of the agents maintaining the models. The cost and technical capacity required to regularly undertake MPI analysis vary with the complexity of the technique, with more sophisticated methods requiring more resources and highly trained staff. In the end, the trade-off between sophistication / complexity and accuracy is cost. In view of the above, trend analysis, stress testing and other traditional surveillance methods should be used together with EWS models for macro-prudential analysis.

\section{A System of MPIs in Form of Composite Indicators for Kazakhstan}

The focus of financial vulnerability in this paper lies on the banking sector. The reason for this is the fact that the ratio of equity capital in many Kazakh companies of the nonfinancial sector is relatively low and the capital market - particularly the corporate bonds market, but also the stock exchange - is still rather underdeveloped. Thus, companies in 
Kazakhstan have to rely on bank credit as a means of financing more than in many other countries. The health of the banking sector and its ability to provide credits to companies and individuals in a sufficient quantity and quality is thus even more important in Kazakhstan than in other countries where the issuance of stocks and bonds may offer the possibility - at least for bigger companies - to raise capital without relying on bank credit.

The domestic banks in Kazakhstan, on the other hand, have been created mostly in the past 10 to 15 years and thus have not been able to accumulate a comfortable equity basis in a similar way as banks in Western industrialized countries. They still rely heavily on credits from foreign sources, also because the saving ratio of Kazakh consumers is relatively low and thus the relatively cheap source of refinancing via saving accounts is feasible only to a much smaller degree than in most industrialized countries.

\section{IV.1.1 Four blocs to distinguish in our analysis}

(1) Real sector of the Kazakh economy

(2) Banking sector in Kazakhstan

(3) Money- and capital market, current account and other financial markets in Kazakhstan (in short: Financial Market sector) International Economy from a Kazakh point of view

All four sectors are interlinked and a priori it is possible that in each of the four sectors a crisis may occur, eventually affecting the other sectors as well. Thus, for all four blocs a separate indicator system has to be set up which has to be monitored permanently in order to detect any possible impact on financial stability at an early stage. As the causality of a financial crisis may change, further analysis has to engage in the interaction of these four sectors. Note that we developed two composite indicators for the real economy, a leading and a coincident one, so that the overall number of composite indicators will be five.

In the following, the methodology to construct composite indicators is presented. Based on this methodology, the composite indicators for the real economy ("Composite Coincident Indicator" and "Composite Leading Indicator"), the banking sector ("Composite Banking Indicator") and the financial market ("Composite Financial Market Risk Indicator") will be presented and analyzed. The situation for the most important trading partners of Kazakhstan is analyzed in the "Indicator for the International Economic Environment of Kazakhstan", thus giving a picture of the world economy from a genuinely Kazakh point of view. This particular indicator, however, is constructed in a different way than the composite indicators.

\section{IV.2 The Construction of the Four Composite Indicators}

We construct each composite index following the conventional NBER procedure currently maintained by the Conference Board. Moreover,

1) All selected series are seasonally adjusted, transformed into stationary series (applying the Hodrick-Prescott Filter) and standardized in such way that those series giving a clearer 
signal (i.e. having a smaller variance) get a higher weight in combining the individual series into a composite indicator (more technical details see below).

2) All series with no monthly periodicity, e.g. being published only in a quarterly rhythm, are transformed into monthly series by applying an algorithm proposed by Eurostat (using the Ecotrim software). By this transformation it is guaranteed that at the end all individual components of the five composite indicators are monthly series.

In the paragraph below the individual steps are listed which should be followed to set up such a system, taking monthly time series as given.

\section{Assembling the indicators}

1. Calculate seasonally adjusted variables using the X12-ARIMA method.

2. Trend removal using Hodrick-Prescott Filter.

3. Weighting by using the inverse of the standard deviation.

4. Adding up the weighted elements of the several time series for each month, thus obtaining the weighted sum $s_{t}$

5. Building the index using a recursive formula $(I=$ Index Value, $s=$ sum of weighted components)

$$
I_{t}=I_{t-1} * \frac{200+s_{t}}{200-s_{t}} \quad, \text { starting with the initial value } I_{0}=100
$$

In the following, we name the composition of all five indicators and shortly explain why we chose them. We start with the indicators for the real economy, followed by the ones for the financial sector (financial market risk and banking sector) and the international economy.

Additionally, we present diagrams of the single indicators in the composite indicators during the time the composite indicator in question spans. The names of these single indicators are the same we used in our calculations; however, they appear exactly in the same order as in the verbal explanations. For a more detailed explanation which sources we used and how exactly the single indicators were constructed, please see the appendix. Most importantly, remember that the single indicators have been deseasonalized and treated by a Hodrick-Prescott-Filter in order to remove their trend. This mainly explains their possibly unfamiliar shape.

\section{IV.2.1 Composite Leading Indicator for the Real Economy (CLI)}

1) Oil price (rate of change, $y-0-y)$ : The oil price is the single most important external factor in Kazakhstan, as more than $50 \%$ of the Kazakh exports are linked to oil.

2) US Leading Index (rate of change, m-o-m): As the leading economy in the world, the USA is of crucial importance for the Kazakh economy as well as for all its trading partners. 
3) Ifo World Economic Survey (WES): The survey is based on the assessment of the current economic situation and of perspectives for economic development by over 1100 accredited economists from about 90 countries. Thus, the survey results give useful hints how international investors see the Kazakh economy.

4) $\mathrm{M} 2$ growth (rate of change, $y-0-y$ ): According to all experience, the money supply $M 2$ is a leading indicator for the real economy, as it comprises variables like the money multiplier, lending behavior and central bank policies.

5) Real stock price (rate of change, m-o-m): The development of stock prices reflects the confidence of financial investors about the real economy and thus often gives an impression of the economic development to come.

Expectations of companies in the producing sector (for three months, balances): The producing sector is of special interest according to international experience. Surveys among the factual decision-makers of the economic process, i.e. the entrepreneurs, are a valuable tool of predicting further economic developments. These expectation-based series today are worldwide regarded as important leading indicators by the forecasting community. According to experience in other countries, a change in direction for three consecutive months signals a cyclical turning point with a high probability (Nerb, 2004).

6) Industry, Manufacturing of Industrial Products

7) Industry, Demand for Finished Products

8) Industry, Stock of Finished Goods

Figure 2: The Composite Leading Indicator for the Real Economy

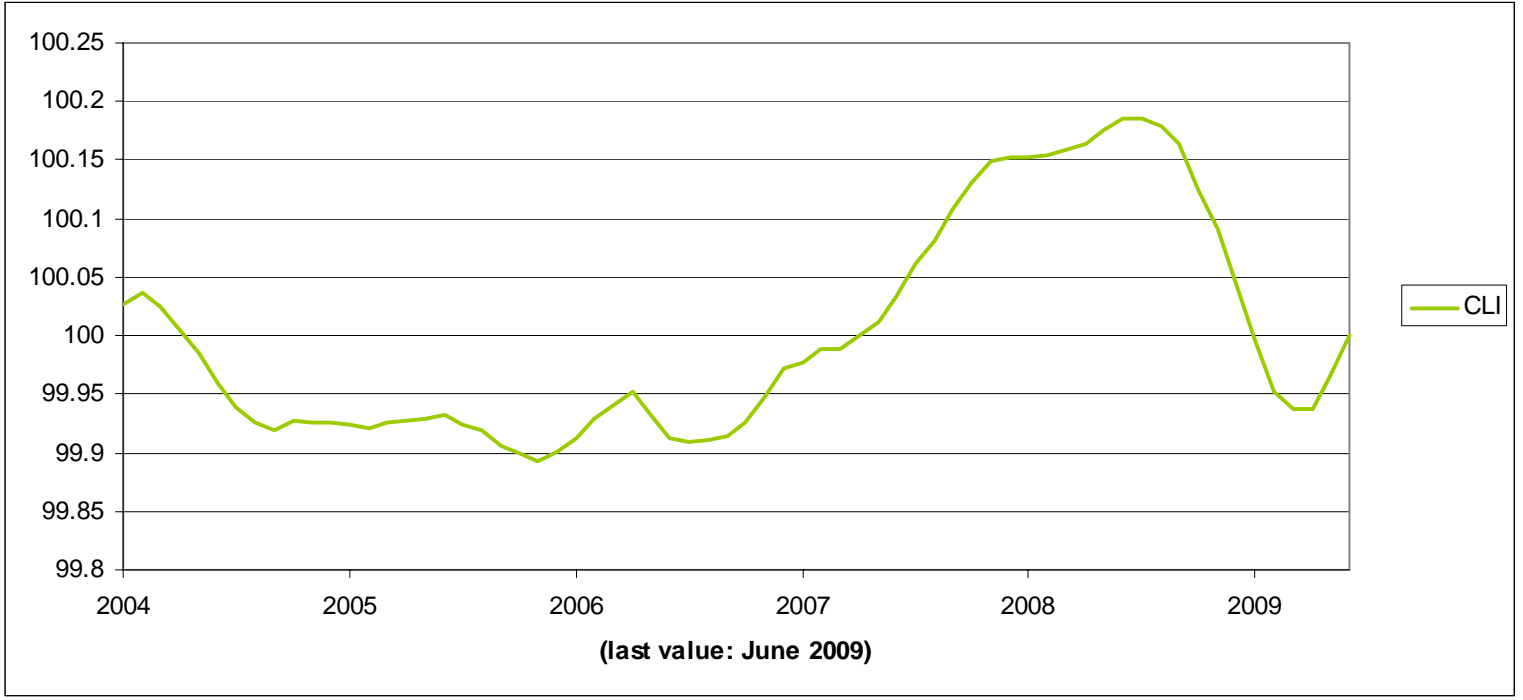




\section{IV.2.1.1 The Components of the Composite Leading Indicator (CLI)}
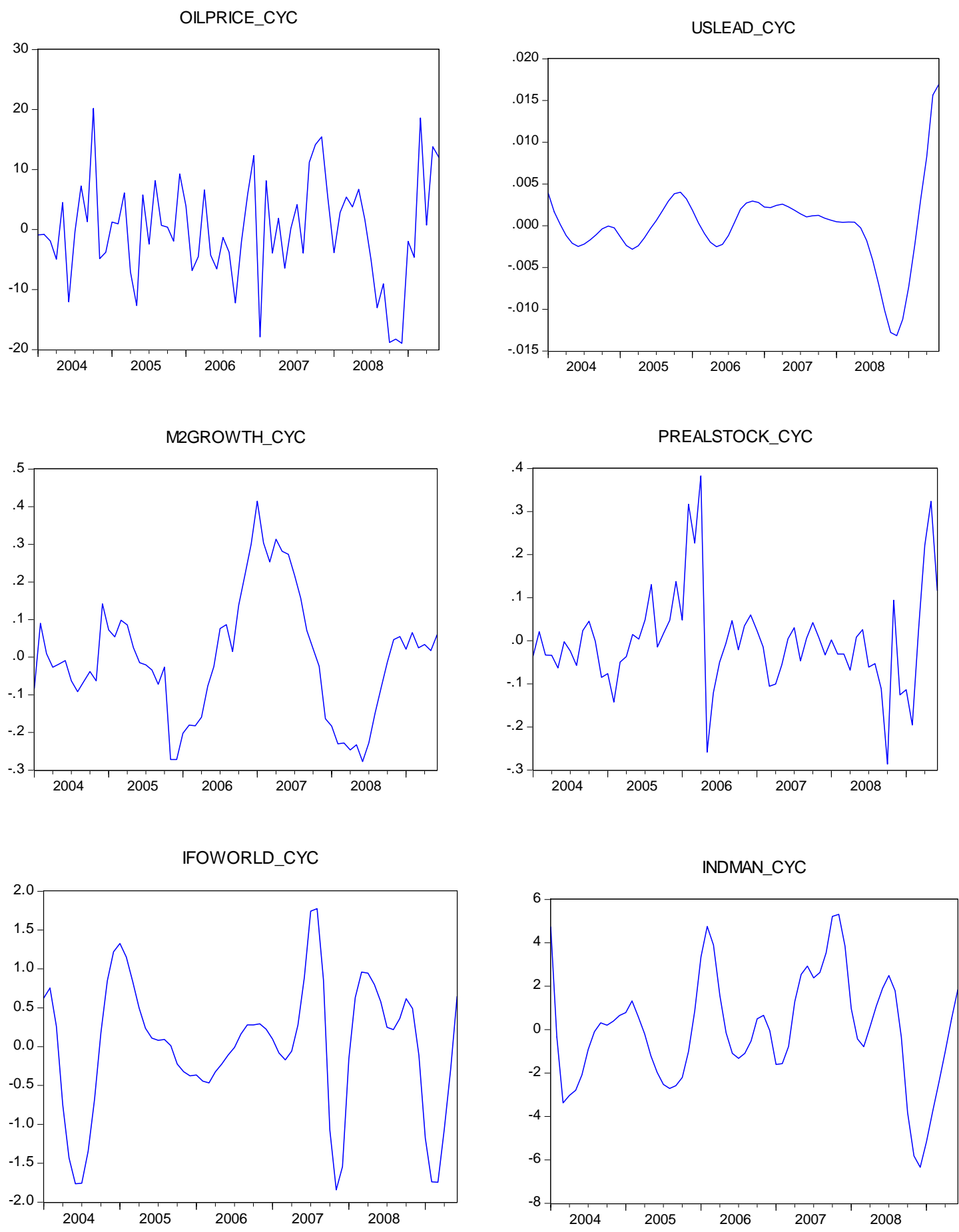

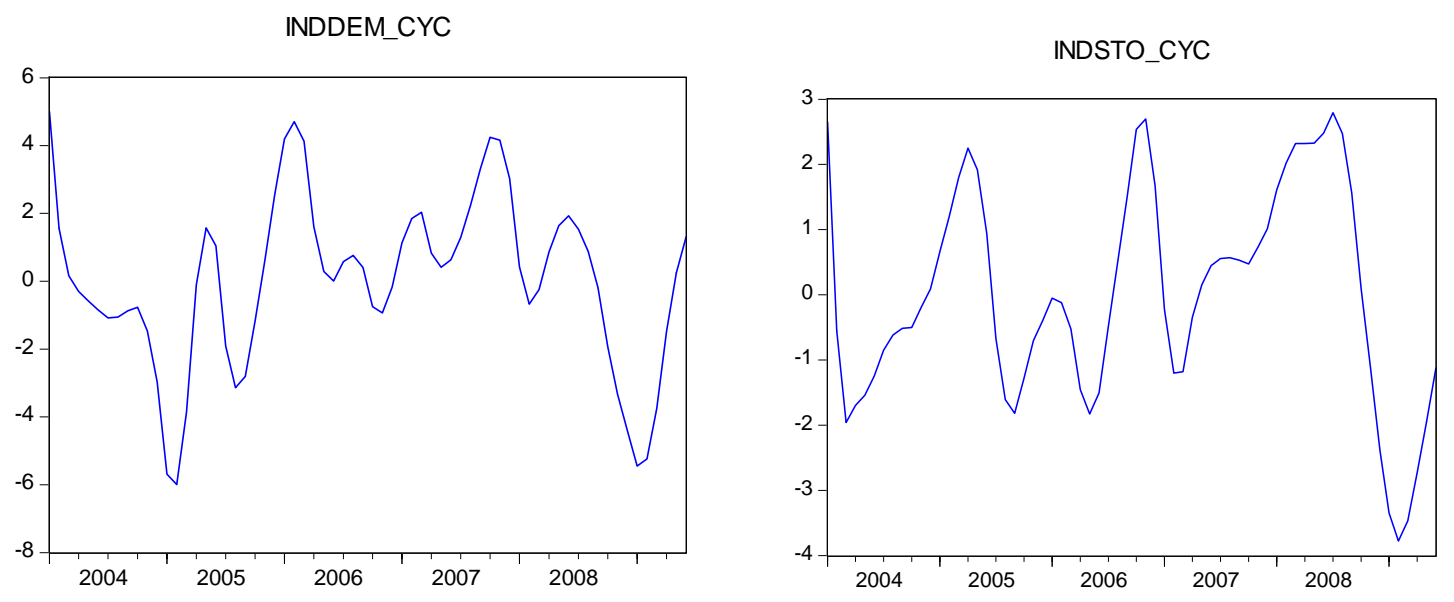

\section{IV.2.2 Composite Coincident Indicator for the Real Economy $(\mathrm{CCl})$}

1) Activity Index of Total Production (rate of change, m-o-m): The Activity Index is a traditional and apparently proven measure of the Kazakh authorities for the overall economic activity. It has certain parallels to the Gross Domestic Product (GDP), which is more commonly used among economists around the world.

2) Economically Active Population: An increase in the working population - be it through an increase of the labor force or through lower unemployment - normally coincides with economic growth and thus is a good measure of the economic state of the nation.

3) Real Wages (nominal wages / CPI): Real wages increase when labor is relatively scarce or labor productivity is growing. As long as it is not due to political but economic interests, an increase in real wages is a measure of economic well-being.

4) Retail Trade Volume (nominal total trade volume / CPI): When more goods are produced and traded, retail trades are most likely to increase at least proportionally. Thus, they are a good indicator for economic activity as well. 
Figure 3: The Composite Coincident Indicator for the Real Economy

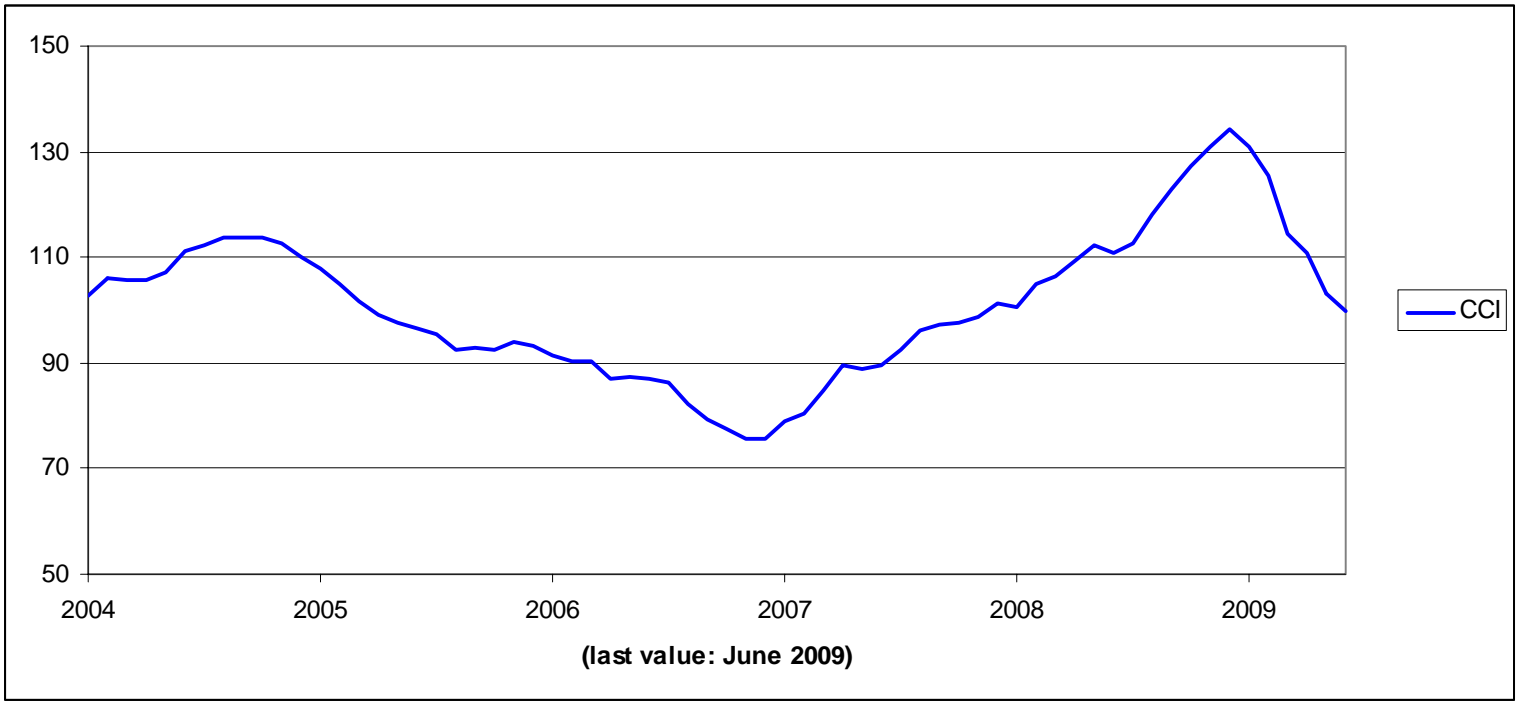

\section{IV.2.2.1 Components of the Composite Coincident Indicator (CCl)}
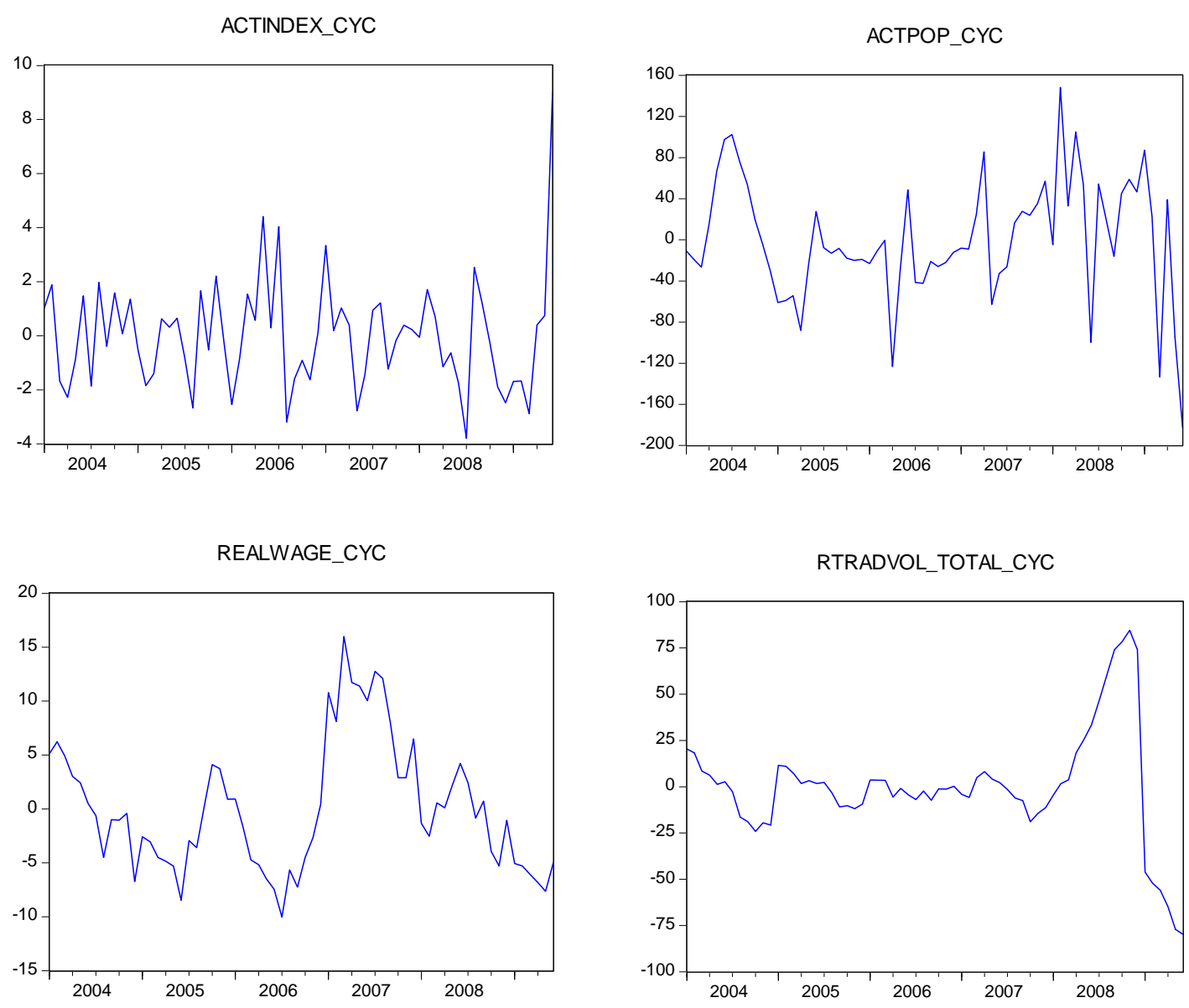


\section{IV.2.3 Composite Banking Stress Indicator (CBI)}

1) Long-Term Foreign Liabilities of Banks in relation to Foreign Assets of Banks: A rising ratio signals the dependence on foreign investors' confidence which can decline for various reasons, affecting seriously the banking sector in Kazakhstan.

2) Ratio of Bank Loans to Trade, Construction and Industry over Total Loans: An overinvestment of these private sectors traditionally strongly influenced by the business cycle could lead to a deterioration in the quality of the banks' credit portfolios.

3) Total Loans Growth (y-o-y): A high growth rate may indicate coming stress in the banking sector and a low level of liquidity to respond to shocks, e.g. if the growth rate is unjustified as risks are underestimated.

4) Real Credit Costs for Bank Clients (Interest Rate Companies are Paying to Banks Inflation): High credit costs tend to slow down investment and thus activity in the real economy and these costs hint to an insufficiently (imperfectly) competitive banking sector, which in turn makes single banks "too big to fail" and thus can lead to moral hazard effects and irresponsible risk-taking.

5) Profitability of Banks (Interest Rates Companies Pay - Interest Rates on Treasury Bills): Unusually high profitability may be a sign of excessive risk taking or a bad risk assessment procedure in the banking sector, both of which increase the overall risk for this sector.

6) Liquidity Risk (M2/Total Loans): An increase of this indicator signals that the increase of money supply (money multiplier) is driven by credit growth. Even in case of a reduction of the monetary base by the central bank, a high money multiplier will accelerate the growth of M2 (as well as of M3 or other money aggregates) and thus increase the danger of inflation, which sooner or later can make necessary more restrictive monetary policy measures hurting the banking sector.

Figure 4: The Composite Banking Indicator

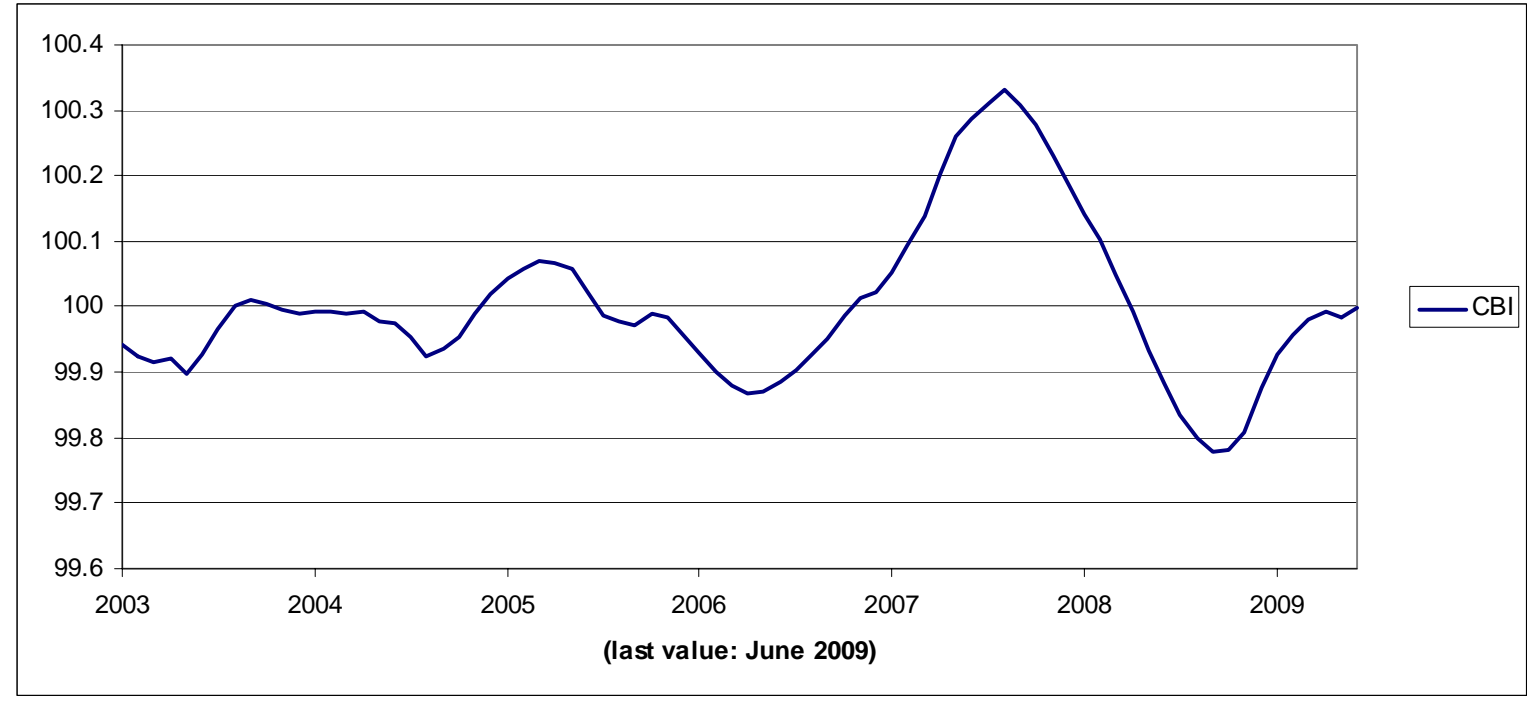




\section{IV.2.3.1 Components of the Composite Banking Stress Indicator (CBI)}

LIAB_ASSETS_CYC

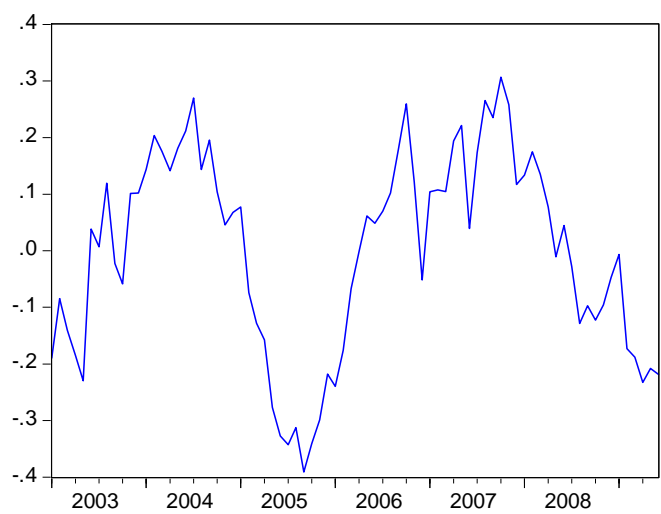

LOAN_GROWTH_CYC

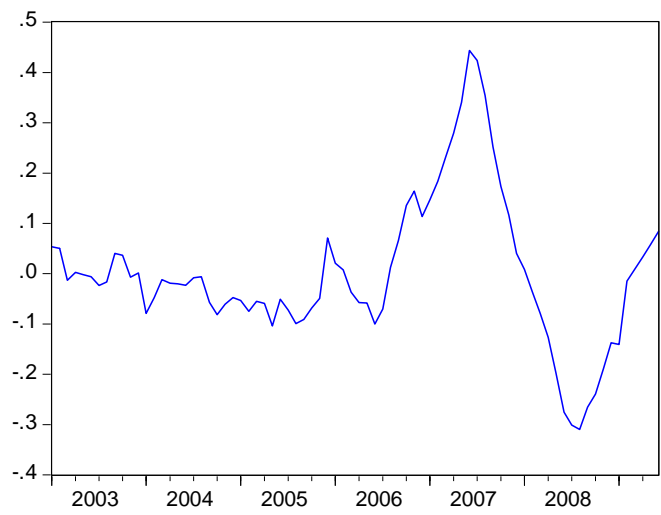

PROFIT_CYC

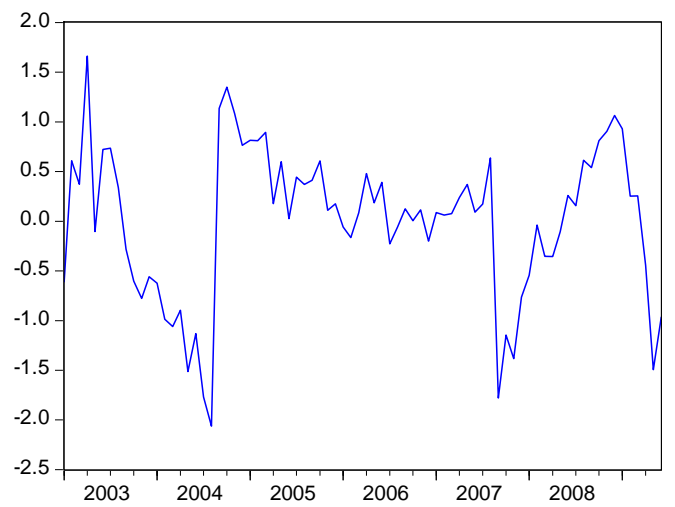

LOAN RATIO_CYC

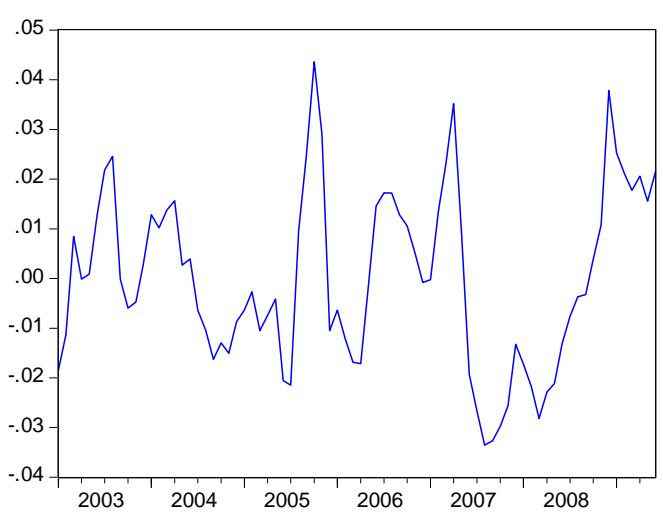

IR_INFL_CYC

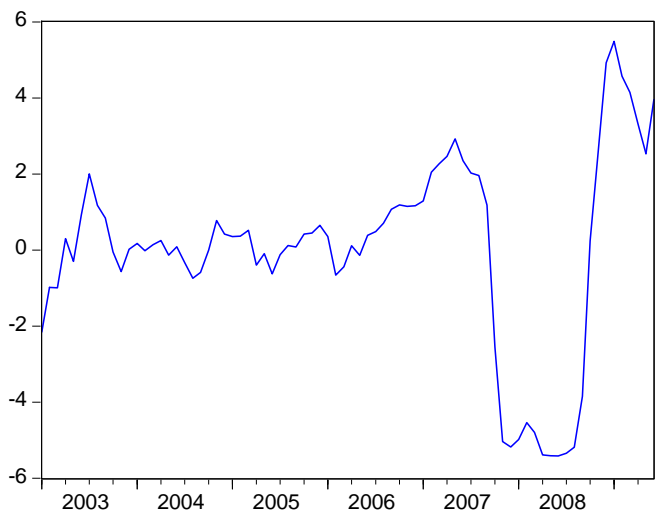

M2_LOANS_CYC

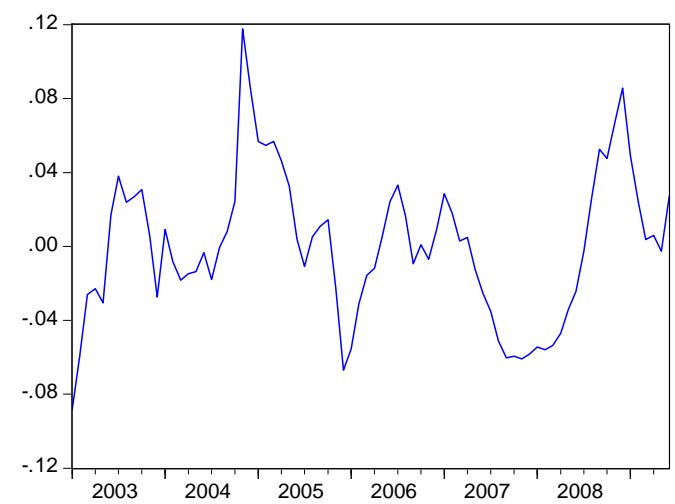




\section{IV.2.4 Composite Financial Market Stress Indicator (CFMI)}

1) M2/Foreign International Reserves: High growth of this indicator can signal excess liquidity that may fuel speculative attacks on the currency and lead to a crisis.

2) Growth of the inverse Real Exchange Rate (rate of change, y-o-y): In standard textbook economics, a rise of the real exchange rate is a bad sign for a developing country or transformation economy if it does not coincide with an adequate rise in productivity. However, this point is often made regarding resource-poor countries relying on an industrial export sector like for example China or Eastern European countries.

In a resource-rich country like Kazakhstan, things are a bit different. Here, a high level of the real exchange rate seems to be a sign of strong foreign investors' confidence. The fact that foreign, e.g. American, investors accepted a strong Tenge although inflation rates were much higher than in their home country seems to have been more vital for the Kazakh economy than the loss in competitiveness for the exporting sector. Accordingly, our Real Exchange Rate indicator moves upwards (and thus signals a higher risk for the Kazakh economy) when the Kazakh currency loses against the American currency in real terms (see the sub-chapter III.3.3.2 for some empirical background).

3) World Interest Rate Differential (KAZ Treasury Bill Rate - Rate of US Treasury Bills):

A growing differential can signal worsening of the confidence of national and international investors in Kazakhstan financing its debt in relation to the US financing theirs. High growth can indicate an expected increase of interest rates in the medium and longer term, which may be caused by an expected increase of inflation and/or doubts in the state's capability to settle its public debt.

4) Current Account balance/GDP (multiplied by minus one): A growing current account deficit - in relation to overall economic activity as measured by GDP - may signal that in the longer term financing problems may arise, as when foreign investors lose their confidence that the public debt can be financed in the long run. Thus, a declining ratio of current account to GDP increases the overall financial risk of a country and a raising ratio reduces it. 
Figure 5: The Composite Financial Market Indicator

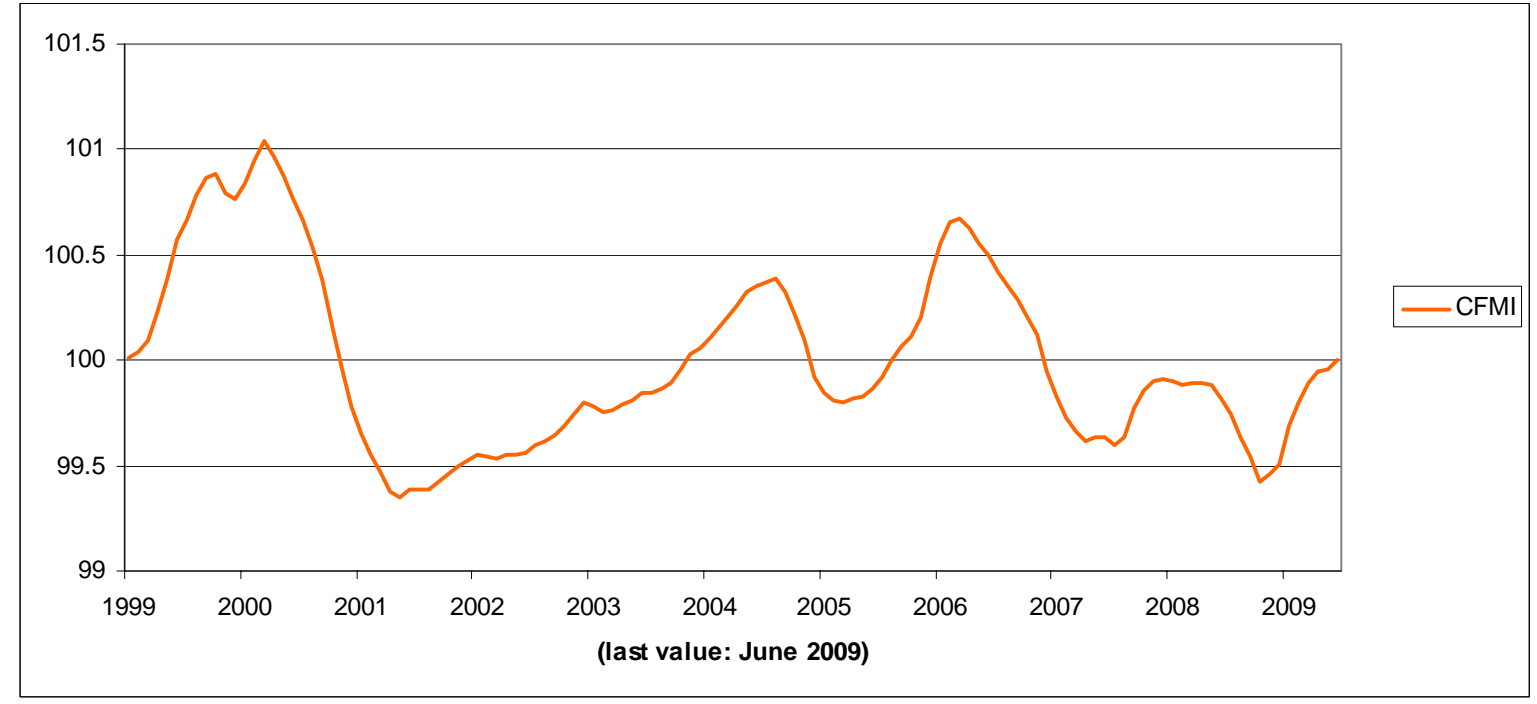

Note: As the figures for the current account are published with a greater delay than the other components of the CFMI, we checked how the overall composite indicator would perform if based only on the first three components (M2/Foreign Reserves, Inverse Real Exchange Rate Growth and Interest Rate Differential). As can be seen in the next figure 5, the diagram is still similar in its large peaks to the one based on the complete set of indicators. Thus, we propose the construction of a preliminary version of the CFMI as soon as the first three series are available.

Figure 6: The Composite Financial Market Indicator without the (CA/GDP)-Indicator

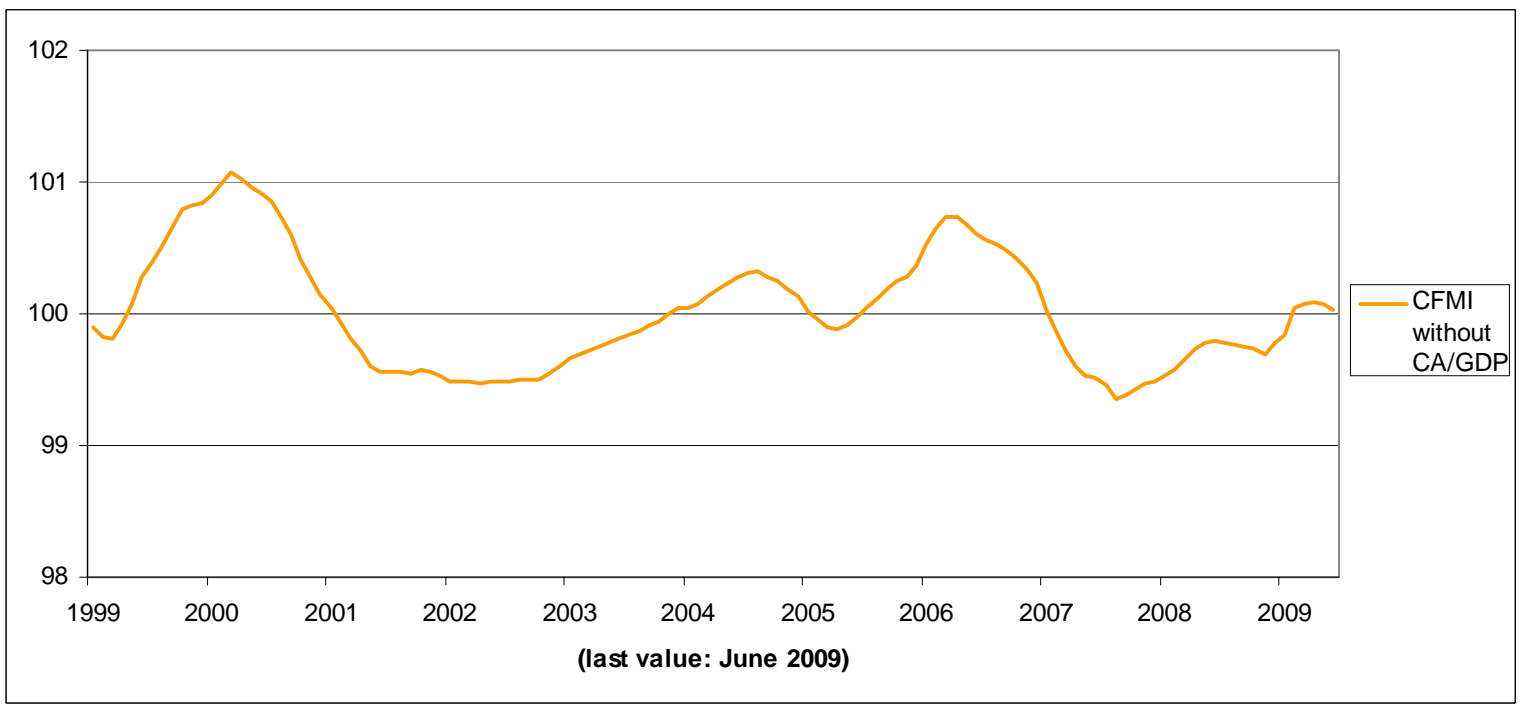




\section{IV.2.4.1 Components of the Composite Financial Market Risk Indicator (CFMI)}
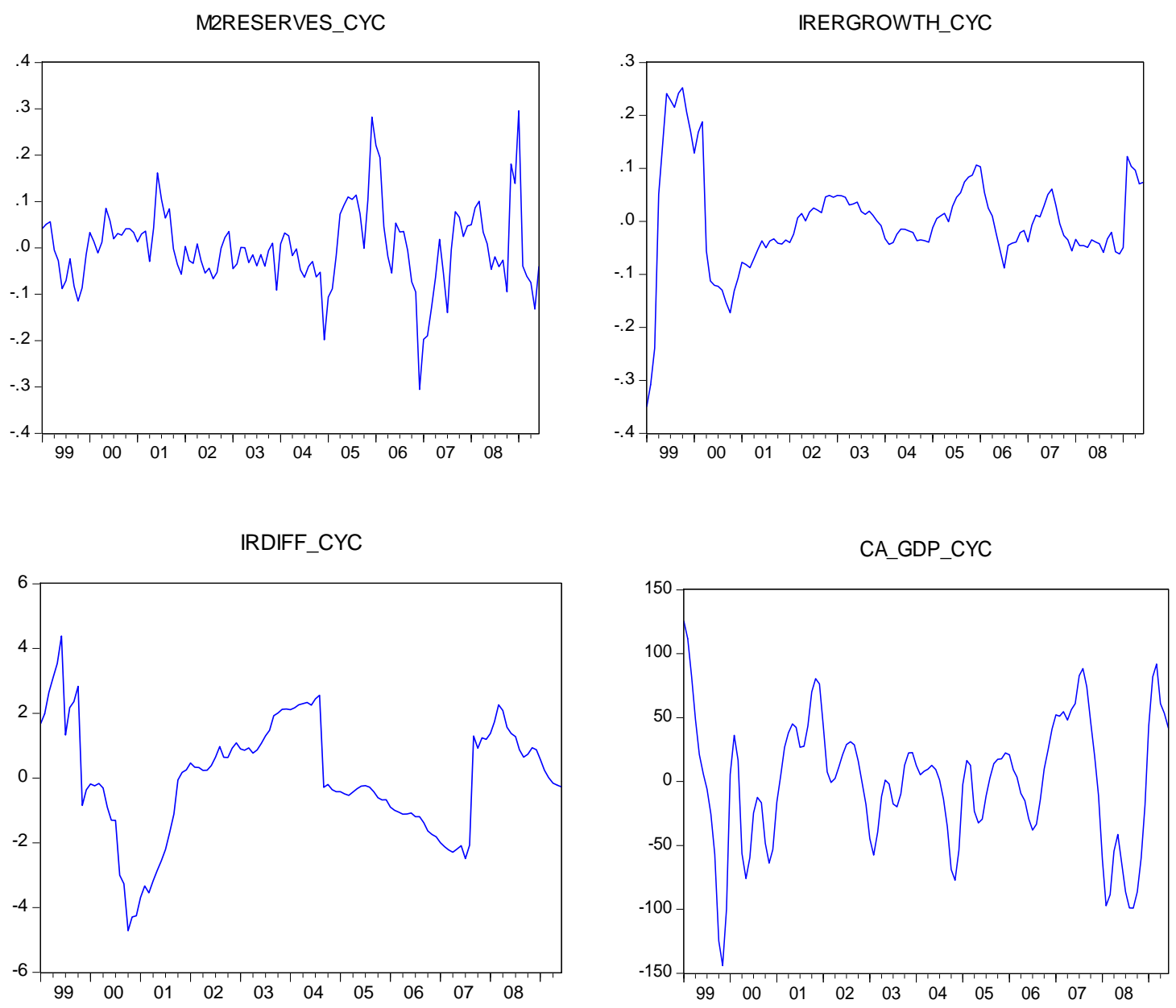


\section{IV.2.4.2 Outlook: The Real Exchange Rate in a Resource-Rich Country like Kazakhstan}

Figure 7: The CFMI without the inverted Real Exchange Rate (CFMI-IRER) and the IRER Indicator itself (IRERI), both against the CBI shifted 15 months backwards (all standardized)

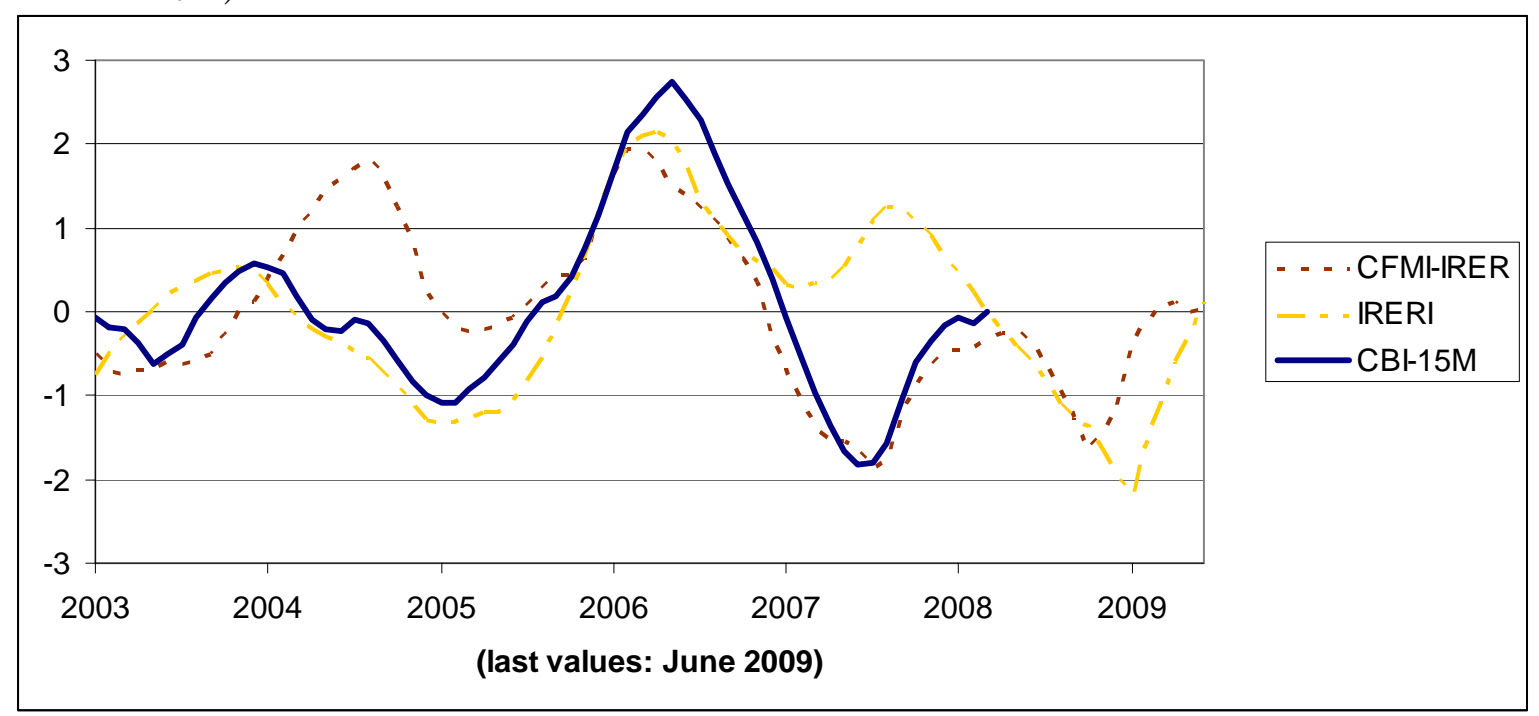

As one can see, the CFMI without the IRER and the IRER-Indicator itself have a quite similar run, reaching a clear peak in February and March 2006, respectively as well as an all-time low in October 2008 and January 2009, respectively. This similar run during the peak of the current financial crisis is the reason why we included the inverse of the standard Real Exchange Rate Indicator in our CFMI.

Furthermore, the correlation of the CFMI with the inverse RER is 0.7587 , while for the CFMI with the standard RER, this value is just 0.5793 .

\section{IV.2.5 Indicator for the International Economic Environment of Kazakhstan (IEEK)}

This summary indicator is based on the Ifo World Economic Survey (WES) and its construction is different from the other composite indicators. Although its outcome cannot be influenced by the Kazakh authorities, it nevertheless gives important details about the Kazakh economic situation: While the outlook for the Kazakh economy itself is part of the Composite Leading Indicator, the IEEK gives a picture of the world economy from a genuinely Kazakh point of view. The survey has been conducted by the Munich based IFO Institute for Economic Research for more than 20 years among more than 1100 economists of national and transnational organizations in over 90 countries. Global players like the organization of the International Chamber of Commerce in Paris, industrial companies like Siemens, big banking organizations like the HSBC group etc. closely cooperate in the WES.

It is an average of the economic outlook for all the countries where Kazakh exports go to, weighted by their imports and thus their importance for the Kazakh export sector. As in 
any Ifo business climate index, the many questions asked in the WES finally yield the two components "Assessment of the Current Economic Situation in the Country" and "Expected Economic Trend in the Country at the End of the Next Six Months". Thus, it is the arithmetic mean of judgment of present and expected (6 months) economic situation, with the answers reaching from 1 (which means "bad") to 9 ("good"), and proved to be particularly well suited as leading indicator. Thus, the economic climate data in the 10 most important foreign markets based on the Kazakh export statistic are weighted according to their share in Kazakh exports.

This "external economic climate" for Kazakhstan of course cannot be influenced by Kazakh economic policies; still, it is an important indicator for the impulses coming from outside the country during times of economic crisis. As we can see, the IEEK fell much more during the actual crisis than it did during the other relatively recent crisis in 1997/98, so that we should expect less positive impulses from Kazakhstan's trading partners this time. The recovery process of the Kazakh economy thus might be rather slow due to an overall slowdown of the world economy.

Figure 8: The International Economic Environment Indicator

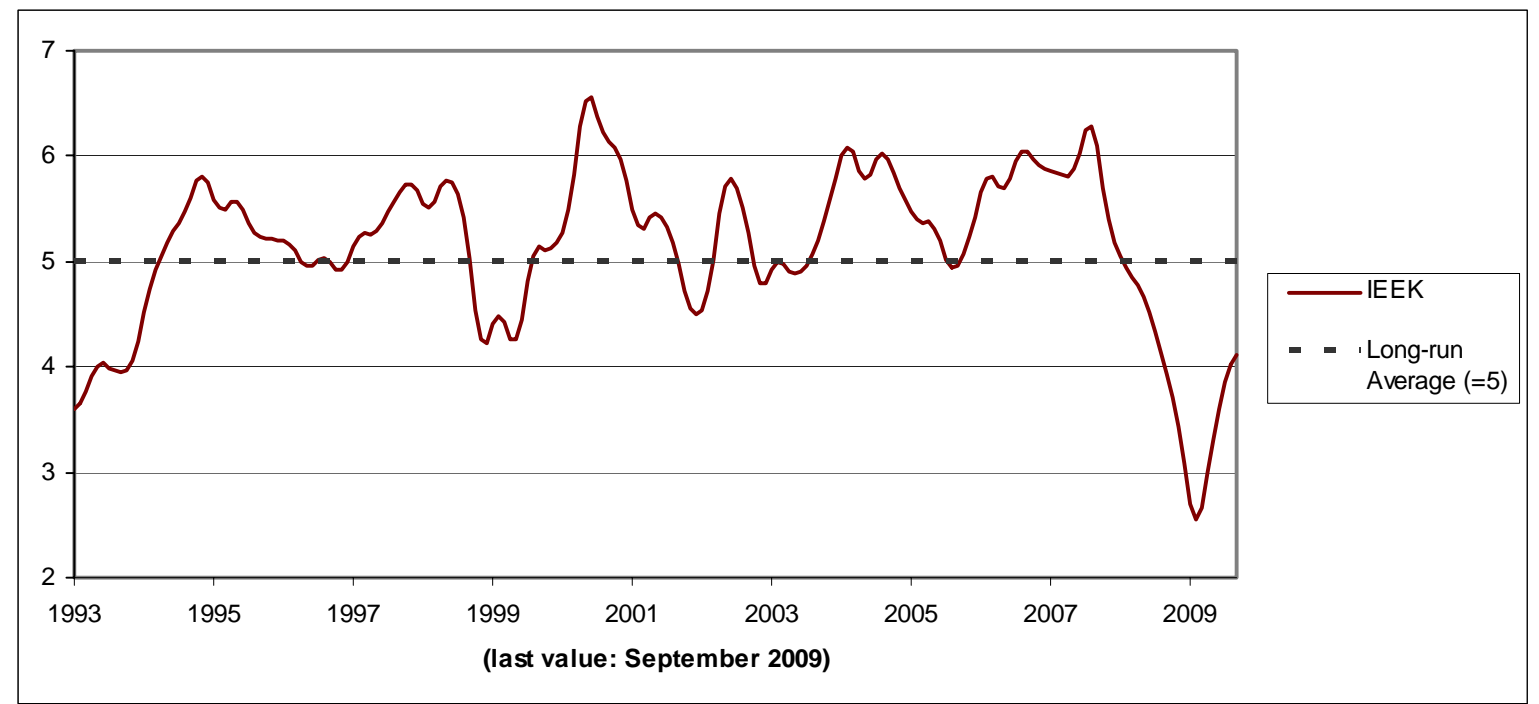

The IEEK is a weighted average of respective data for Italy (16), Switzerland (16), China P.R. (12), Russia (10), France (8), Netherlands (5), Iran (5), UK (3), Ukraine (2), Israel (2), Spain (2), Romania (2 and, Rest of World (17).

In the period 1993 to 1st quarter 1999, Iran, Ukraine, Israel and Romania are not included.

Source: Ifo World Economic Survey (WES III /2009) 


\section{IV.3 Analyzing Current and Future Trends - the Interaction of the Composite Indicators}

In the case of the Composite Leading Indicator for the Real Economy (CLI) Indicator, an increase in the overall indicator signals a cyclical pickup of the real economy. The other way around, a decline signals a slowdown of overall economic activity.

Figure 9: Comparison of the Composite Leading Indicator and the Composite Coincident Indicator (both standardized)

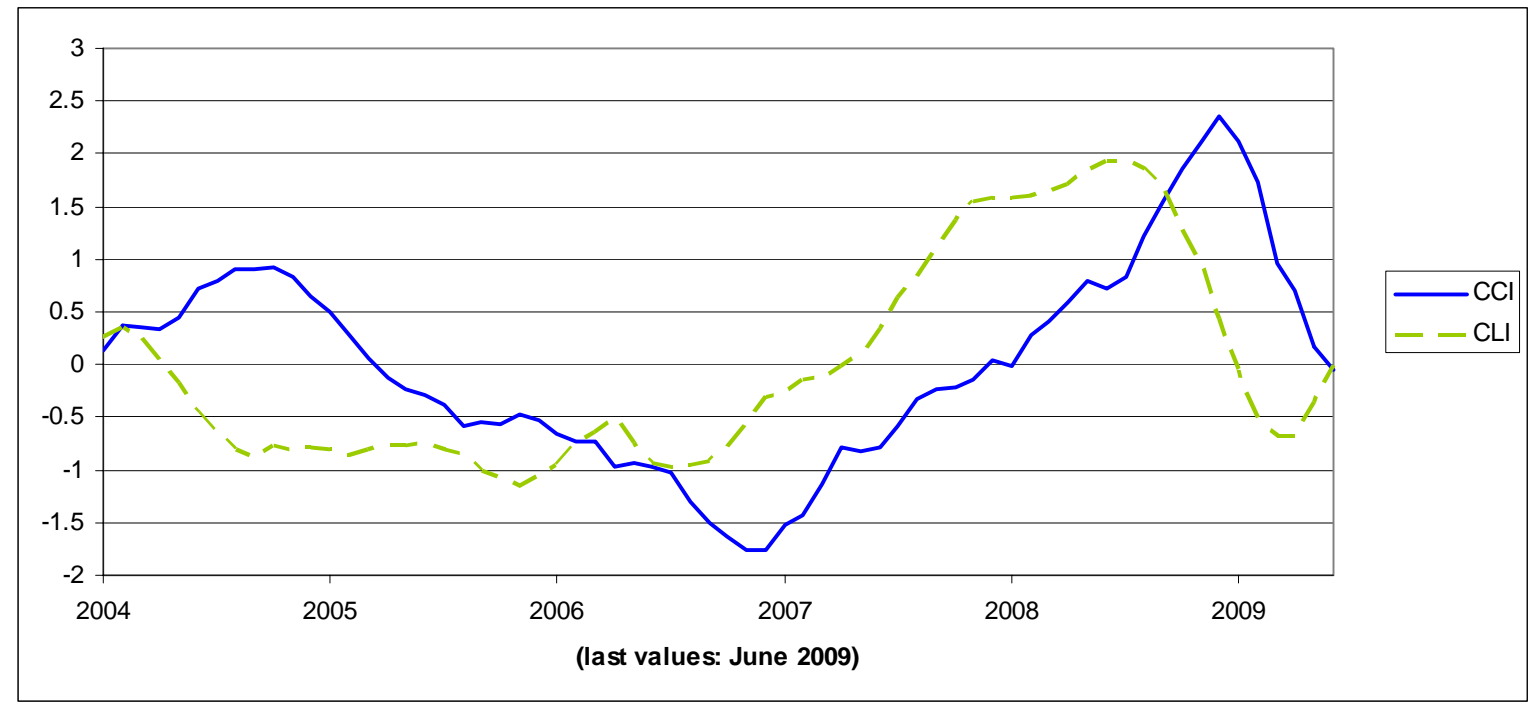

Note: As the CLI and CCI have different volatilities and levels even though their components have been HP-filtered (see Part IV.5 below), it is useful to standardize the variables to obtain comparable results. Therefore, we simply subtract the mean of the whole series from each of its values and divide each of the obtained differences by one standard deviation of the whole series. For further descriptions concerning the construction of the indicators, see the appendix.

This comparison of the CLI with the Composite Coincident Indicator shows a relatively reliable lead of the CLI by about seven months.

In the case of the Composite Financial Market Risk Indicator (CFMI) an increase of the indicator signals a growing market risk. This is not to say that every slight increase already signals an imminent danger for the financial system in general or the banking sector in particular. As can be seen in Figure 4, the CFMI already had a certain peak during summer 2004, without a following strong reaction of the CBI - maybe appropriate political actions had been taken or other factors favored a quiet cooling-down of the financialsector risk. However, for the political side a growing awareness appears to be appropriate when the indicator rises considerably, as a strong increase of this indicator beyond the threshold is quite probably associated with dangers for the banking sector and the real economy. Corrective political measures may be a precautionary tightening of monetary policy - even if the inflation rate is not causing problems at the moment - or other measures to avoid the creation of bubbles in certain market segments, like real estate or share prices. For example, one measure could be to raise the requirements on equity necessary for purchases on credit in those segments.

On the other hand, when the composite indicator is slowing down after a boom, this cannot necessarily be interpreted as that the danger of the outbreak of a banking crisis is 
diminishing. The decline of the Composite Financial Market Risk Indicator may namely be triggered by a significant depreciation due to a "sudden" stop of capital inflows. Liquidity restrictions will likely have a negative impact on credit, particularly when the banking sector relies heavily on cross border loans as is the case in Kazakhstan. In such cases the real economy is also entering a recession, as was the case in Kazakhstan after spring 2008. This can be the final trigger of the banking crisis or even if the banking crisis does not immediately follow, it can be a serious problem for the banking sector as the economic slowdown and higher unemployment will have a negative impact in the form of a rising share of non-performing loans. Thus, from a political point of view, it is very important to prevent a sizable increase of the Composite Financial Market Risk Indicator beyond the upper threshold right from the beginning. However, if this cannot be achieved in time, a decline of the indicator is not a signal that a banking crisis and a recession in the real economy will necessarily be avoided. Thus, the whole system of the different composite indicators has to be kept under strict observation in order not to make mistakes in the timing of corrective measures.

Like in the case of the Composite Financial Market Risk Indicator, an increase of the Composite Banking Stress Indicator (CBI) above a certain threshold - sometimes defined as the long term average plus/minus one standard deviation - signals a looming risk which should alarm particularly the banking supervision, but also the general monetary and economic policy.

As we will see in the following diagrams, the Composite Financial Market Risk Indicator (CFMI) shows a lead of several months compared to the Composite Banking Stress Indicator $(\mathrm{CBI})$ in the case of Kazakhstan.

Figure 10: Comparison of CFMI and CBI

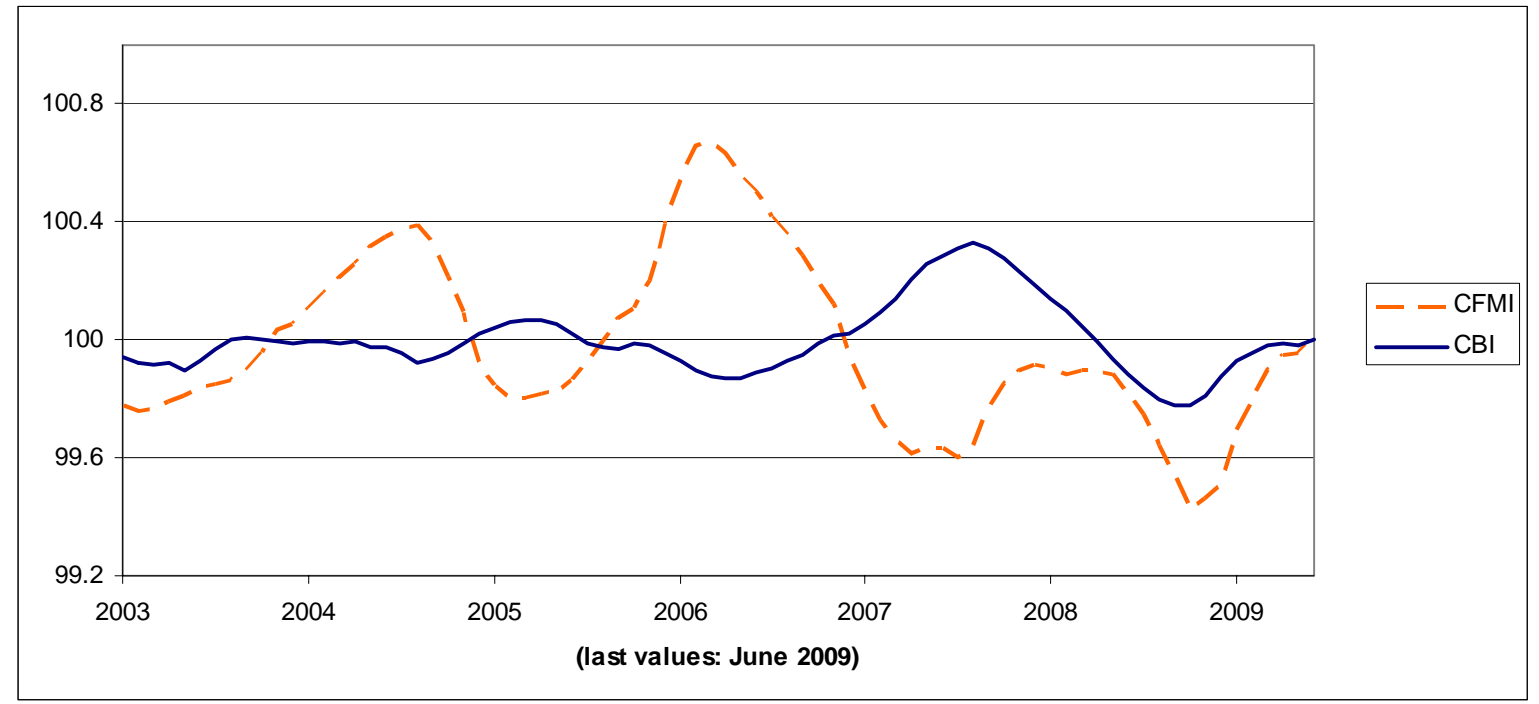


Figure 11: Comparison of CFMI and CBI (both standardized)

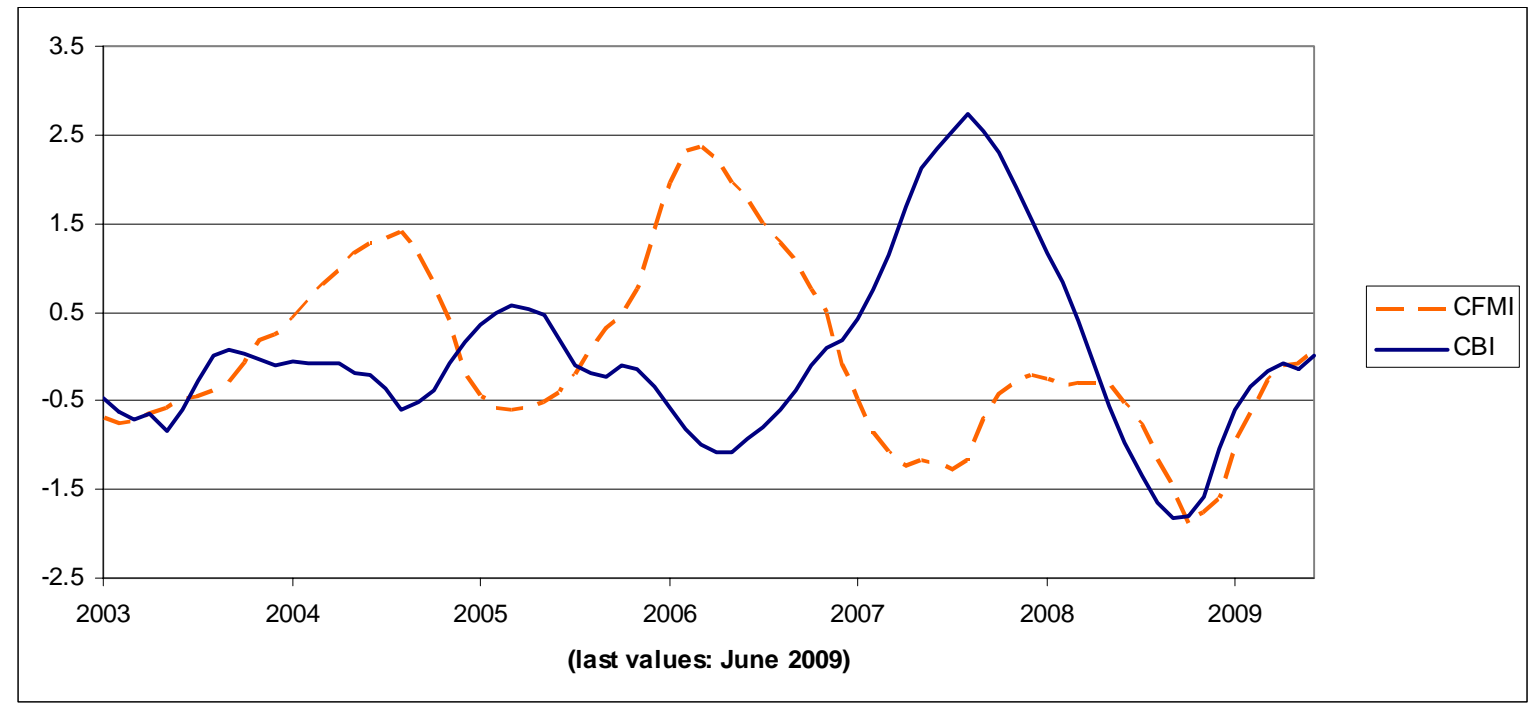

For these (admittedly rather short) time series, we observe a clear lead of the CFMI to the $\mathrm{CBI}$, although the time that it takes the banking sector to "react" to a growing risk in the overall financial sector seems to vary between 7 and 15 months. 7 months is the time between the first peaks (August 2004 and March 2005 for the CFMI and CBI, respectively), while the "cooling-downs" in March 2005 and April 2006, respectively, show a lag of 13 months. Still, as the peaks preceding the current crisis, in March 2006 for the CFMI and in August 2007 for the CBI, are clearly outstanding in their amplitude, a lead of 15 months - as between these peaks - reaches the highest degree of correlation when comparing several different lags. The different values for specific lags were:

$\begin{array}{cc}\text { lag of ... months } & \text { correlation coefficient between CFMI and CBI } \\ 12 & 0.6120 \\ 14 & 0.7418 \\ 15 & 0.7587 \\ 16 & 0.7393 \\ 18 & 0.6096\end{array}$


Of course, this lead is a rather raw estimation, as the data set is not yet very large. Still, even without any quantitative specification, we can state qualitatively that a high value of the financial market risk, measured by the CFMI, will be followed by a growing stress on the banking sector as measured by our $\mathrm{CBI}$. However, the question of how strong the reaction of the banking sector will be has to be answered by looking at a multitude of macro- and micro-economic factors; for example, the reaction of the CBI on the CFMI's peak in mid 2004 was only a cushioned one, while the CFMl's peak in March 2006 was followed by a relatively even stronger deflection of the CBI. Thus, we conclude that the risk has to be assessed anew and case-by-case for each situation. Therefore, a team of experienced specialists from different areas of research are highly recommended.

Albeit the data are still few, we constructed a prognosis of the banking stress, represented by the $\mathrm{CBI}$, based on a regression on the CFMI with a lead of 15 months.

Figure 12: Prognosis of the CBI by a regression on the CFMI shifted by 15 months

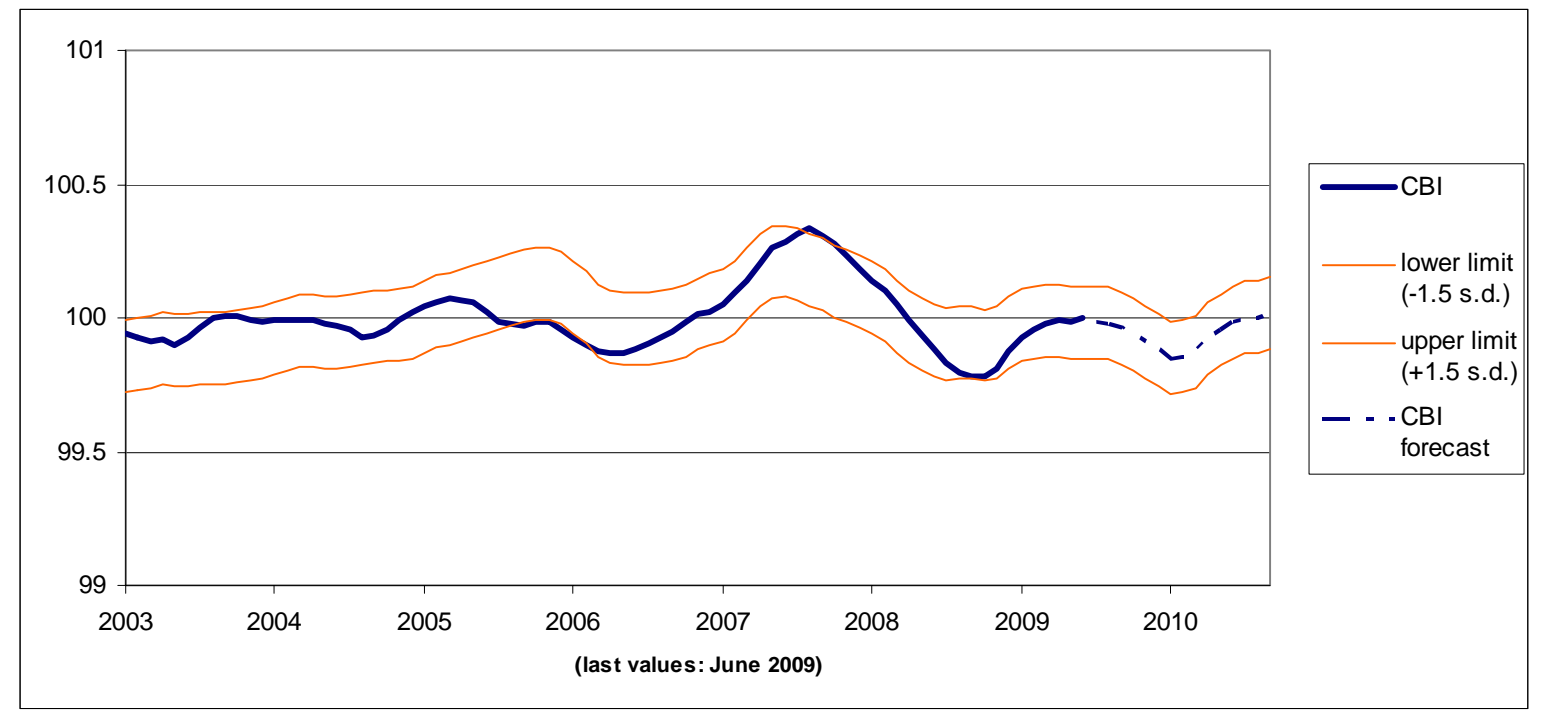

The diagram above shows the $\mathrm{CBI}$ and a prognosis of its future development based upon a simple linear regression on the CFMI shifted forward by 15 months. The slim lines give a band in which the $\mathrm{CBI}$ most probably will lie. They consist of the values of the $\mathrm{CBI}$ predicted ex-post by the CFMI plus/minus 1.5 standard deviations ("s.d."). There are only two outliers, in the winter 2005 and after August 2007, and these are due to the fact that the reaction of the $\mathrm{CBI}$ on the CFMI occurs with a varying time lag. Still, the diagram clearly states that a rising risk in the overall financial sector will be followed by rising risk in the banking sector with a lag of about 5 quarters.

The fifth composite indicator - the International Economic Environment of Kazakhstan (IEEK) Indicator - is more of external nature and cannot be influenced by national policy measures but serves as an indication in which way the world economy (from a Kazakh perspective, as the country results are weighted according to the Kazakh export structure) will develop in the next 6 months. In case that the problems signaled by the other four composite indicators for Kazakhstan take place in an environment of a depressed international environment, national policy solutions are much more difficult than in case of an international environment being in a brighter position than the Kazakh one. At present this is certainly not the case, as the composite indicator for the international economic 
environment of Kazakhstan has reached a new historic low in the first quarter of 2009. In this case it is almost exclusively up to the national policy to take measures in order to prevent or at least soften dangers for the banking sector and the real economy.

Figure 13: The IEEK compared to CLI and CCI (all standardized)

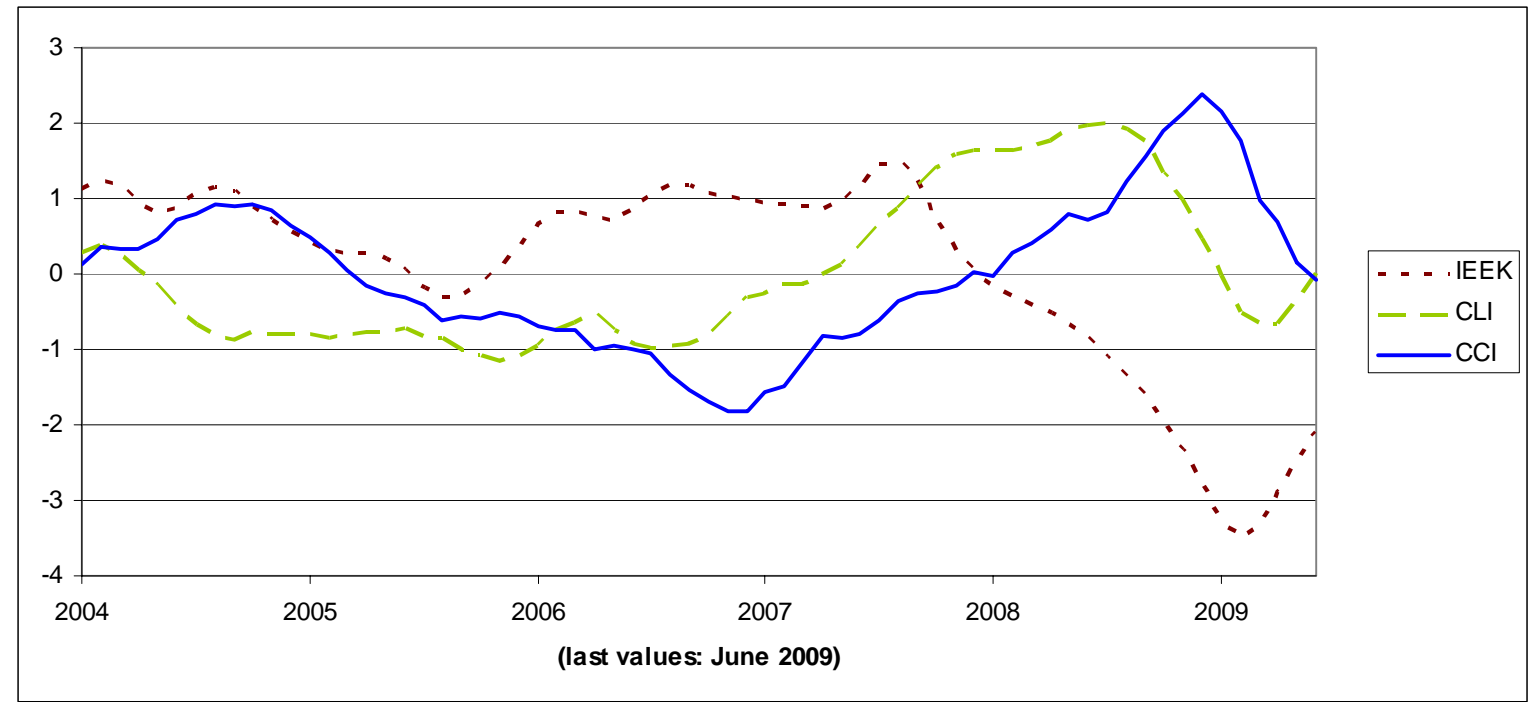

A glance at the run of the IEEK and the indicators for the Kazakh real economy seems to show a developing lead of Kazakhstan's trading partners (or, more exactly, of the importers of Kazakh goods). From mid 2005 on, the world economy picks up faster than the Kazakh one, and while the IEEK decreases rapidly after August 2007, even the Composite Leading Indicator for Kazakhstan remains high until summer 2008.

On the other hand, one should keep in mind that the IEEK is a weighted average of the assessment of the countries' current and future situation by the world's leading economists. That means that expectations are included into the IEEK, which is not the case for the $\mathrm{CCl}$ and only partially for the CLI. Indeed, we can observe a relatively similar development of the IEEK and the Ifo World Economic Survey results for Kazakhstan (forming the "WES" Indicator or "WESI"), which also is one of the 8 indicators forming the CLI: 
Figure 14: The IEEK compared to the Kazakh WES Indicator (WESI) - both standardized

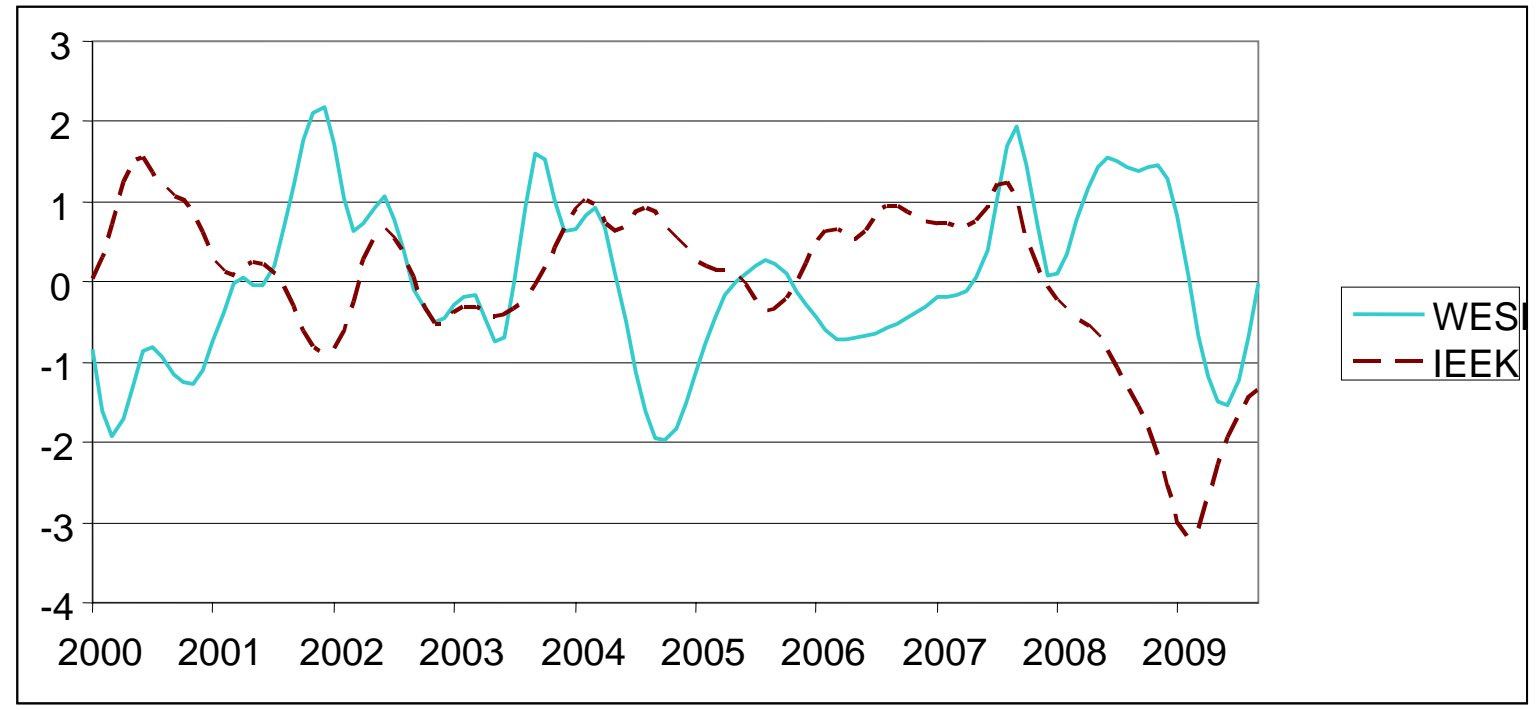

Note: The two indicators do not have a clear statistical relation. The best correlation would be reached by a lead of the IEEK of 5 or 6 months, with a correlation coefficient of less than 0.4. Thus, we can note that there are factors for the assessment of the current Kazakh economic situation other than the economic situation abroad (most notably, the oil price). Still, we can see that the assessment for the importers of Kazakh goods (expressed by the IEEK) fell before the one for Kazakhstan itself in the current slump, showing that the current crisis was clearly induced by foreign influences.

As demonstrated in the chapter on the Composite Banking Stress Indicator and on the Composite Leading Indicator for the Real Economy, both indicators gave a warning signal almost exactly at the time when the banking crisis started. Only the Composite Financial Market Risk Indicator (CFMI) had sent a warning signal long before the banking crisis started - already in spring 2006. Despite a cooling-down of the CFMI in the later part of 2006 and in 2007, the shock exerted on the banking sector by the turbulences in the financial market was so severe that only a more forceful cooling down of the financial risks would have had possibly a chance to successfully prevent the banking crisis, or at least to soften it. As pointed out, such efforts were complicated by the fact that the international economic environment of Kazakhstan had grown severely recessionary. However, the latest available update for the composite indicators (July 2009) signals a softening of the banking crisis and some pickup of the real economy in the latter course of 2009 and early 2010.

\section{IV.4 Policy Analysis and Recommendations}

Continuous monitoring of financial system stability with respect to structural, institutional and macroeconomic aspects is not only crucial in detecting and preventing financial crises, but also in ensuring strong macroeconomic performance and effective implementation of monetary policy at the national level.

The results of the vulnerability assessment will be the basis for the policy recommendations. The given kind of warning signals provides a clue on the appropriate policy actions 
needed to address existing or potential weaknesses. Further trend analysis of underlying factors causing warning signals for one particular indicator or a group of them will be a help in formulating policy recommendations.

In general, policy recommendations can be categorized into (i) financial regulation and supervision policies, (ii) macroeconomic policies, such as fiscal, monetary and financial ones; and (iii) policies governing financial infrastructure, such as legislation, payments and settlements systems and financial safety nets (see Figure 1). Ideally, alternative policy actions should be recommended for addressing specific vulnerability. Some examples of policy recommendations are given below.

Typically, financial systems are exposed to credit risk, liquidity risk and market risk (which includes interest rate, exchange rate, and equity price risks). For assessing the soundness of the financial sector, the results of signaling methods should be interpreted in terms of credit, liquidity, and market risks. For example, one problem to address could be a country's credit risk arising e.g. from an excessive growth of the credit-to-GDP ratio, loanto-deposit ratio and of the money supply. This risk may require policy actions such as imposing restrictions on further lending to certain over-heated sectors like real estate and consumer finance. Another measure could be to cap permitted lending by each sector as a share of total lending at $10 \%$. There is also a need for a closer monitoring of credit policy and credit appraisal system. A sharp increase in credit card default may need the imposition of higher minimum salary requirement for credit card holders and setting up a credit-card information bureau to avoid multiple cardholding.

For the fiscal sector, high levels of public debt, fiscal deficit and government consumption relative to GDP could be unsustainable for a country with a narrow export base in case of an economic downturn, poor budgetary performance, or a rise in the real interest rate due to world economic recovery. Effective fiscal management through better tax collection and public expenditure management are required to reduce the debt burden and ensure debt sustainability against sudden shocks.

There is also a time dimension to the range of possible policy recommendations. Policy can be categorized as short-, medium- and long-term in nature, depending on the time required for their effective implementation. Usually, short- and medium-term policies are recommended for high frequency monitoring.

Producing effective policy actions for recommendation relies heavily on the timeliness and reliability of available information. It is therefore important to monitor how close the actual figures are to their threshold value, rather than wait for them to breach the threshold. This is crucial in order to have enough time to implement pre-emptive measures and avoid the crippling cost of a full-blown crisis.

\section{Concluding Remarks}

The financial and currency crises in several developing and transformation countries and their contagion effect in some developed countries revealed the limitations of the current state of monetary and financial monitoring systems in comprehensively addressing the financial vulnerability leading to a crisis. A crisis can cause economic, social and political problems. The cost of a financial crisis could be severe as a result of harsh reserve losses, output decline and increasing poverty. In order to prevent financial turmoil and its 
contagion effect, monitoring of financial sectors as well as spillover effects from weaknesses in the real sector assumes great importance. The monitoring system should be able to detect the magnitude and nature of economic and financial vulnerability at an early stage and suggest appropriate policy actions to address them in order to prevent a crisis.

There is no universally accepted standard for or system of monitoring financial vulnerability. The development of MPIs for monitoring financial vulnerability is still "work in progress". Even with the significant progress in techniques for MPI analysis and especially in EWS models, it is still almost impossible to predict the probability, timing, and nature of a possible crisis. It may be better to use macro-prudential analysis in crisis prevention rather than crisis prediction. A monitoring system should be cost-effective and not too complicated so that most countries can implement it for their high frequency monitoring.

The empirical framework proposed here is based on a set of selected leading macroprudential indicators (MPIs) / financial soundness indicators (FSIs) including business tendency survey indicators which are condensed to four composite leading indicators (plus one coincident composite indicator for the real economy).

The proposed system can provide an initial framework for using MPIs to detect vulnerability in the economy and the financial sector. The vulnerability signals provided by the proposed framework can direct attention to particular issues or problems, and trend analysis can then be used to confirm whether the indicators are indeed showing signs of vulnerability that may lead to a crisis, or whether they are simply a result of institutional or structural changes. In order to avoid the virulence of the contagion among neighboring countries, there is a need for further strengthening the regional surveillance mechanism, particularly the peer review process.

The most difficult part of monitoring is to analyze, interpret, and translate the information contained in these indicators into something that could help direct policymakers and decision makers to appropriate policy action. The interpretations discussed in this paper are meant to be starting-points for national authorities to develop more country-specific monitoring schemes that take into account their special needs and circumstances.

Another important task is to provide the analytical groundwork in devising the appropriate benchmarks or threshold values for higher frequency data. However, it is to be noted that the macro-prudential analysis should focus not only on the symptoms - whether an MPI is above or below the threshold value - but on the underlying sources of chronic vulnerability.

The presented composite indicators as well as the individual components of these summary indicators should be regularly compared to their threshold values. In terms of policy action, it is more important to monitor how close the figures are to their threshold values rather than wait for them to breach the threshold. In this sense, it is important to establish "rules of thumb" when interpreting surveillance results, because there may be several options available. For example, one can opt for a disinflationary policy to avoid sharp deviations of the real exchange rate from its historical trend, or adopt a policy that avoids unsustainable current account deficits.

Despite the appeal of using MPI analysis, its limitation should be recognized. The first major drawback of using MPIs is the underlying assumption that an economy has a consistent and regular pattern prior to a crisis. It relies largely on historical precedents, but because of differences in the origin, severity, and timing of crises, it is possible that indicators that were useful for a past crisis past may not necessarily be so in the future. 
Triggering events for different types of crises also vary, i.e. indicators for a balance-ofpayments crisis may not necessarily be very effective when used to predict a banking crisis. Therefore, the process of identification of MPIs should be dynamic in nature, in order to constantly assess the need for new indicators. Emergence of vulnerabilities in an as yet stable sector or a new type of vulnerabilities may call for the inclusion of innovative MPIs in the surveillance process.

Second, MPIs that are useful for crisis prediction in one country may not be so for another. Reasons are differences in the stage of economic and financial development, giving rise to significant variations in accounting and prudential standards, in the level of financial sophistication, resilience of institutions, etc. However, tailor-fitting the set of MPIs to suit the unique economic characteristics of each country would give rise to the issue of lower cross-country comparability.

Third, structural breaks in the time series arising due to changes in regulations or regimes can complicate MPI analysis. In light of these limitations, caution ought to be exercised in analyzing MPIs or more specifically, applying one smaller core set of leading indicators to a group of countries, and encouraging compilation of additional indicators that apply to a country's specific situation.

Fourth, there are measurement problems in capturing qualitative information. For instance, poor banking supervision, which has been identified as a major factor in the Asian crisis, is difficult to quantify and qualitative assessments may vary significantly. Other factors that are possibly important in predicting a crisis but which are difficult to measure include the quality of corporate governance, independence of the central bank, reliability of the legal system, political stability, and other institutional qualities.

Further development of deeper and more liquid financial markets and strengthening financial institutions will be essential to prevent future crises and financial instability or to minimize their impacts in the region. Such strengthening could include including greater central bank independence, an improved prudential supervision and regulation of financial markets, legal infrastructure, improving corporate governance and greater policy transparency.

Finally, in this paper we focused on quantitative aspects of crisis monitoring. But qualitative aspects are not less important. It is vital that the model should not be allowed to take decisions for us. Models are just tools to help management in decision-making.

Management decisions supported by objective quantitative models help to reduce vulnerability and economic losses. But the experience and judgment of the analyzer is most important. There are several qualitative factors in a model, such as the parameters and modeling assumptions used, as well as choices that relate to characteristics of the underlying data and the historical period form which the data was drawn. Vulnerability-management tools and judgment and experience of the technical staff need to be strengthened continuously. Moreover, macro-prudential analysis requires an inter-disciplinary team, such as financial economists, banking and financial experts, financial institutions supervision experts, accountants, economists, econometricians, corporate sector experts, statisticians etc. and the scope of capacity-building in monitoring is still wide among developing and transformation countries. Technical training should be provided to members of the ministry of finance, the central bank and capital-market and other relevant supervisory authorities in order to enable them to perform meaningful interpretation and analysis of MPIs. Effective monitoring calls for a high degree of experience in analyzing the quantitative 
MPIs, coupled with informed judgment on the adequacy of the institutional and regulatory framework of the concerned country. 


\section{References}

Agenor, P.R. (2002) "Does Globalization Hurt the Poor?" World Bank Working Paper 2922

Agenor, P.R., (2003). "Benefits and Costs of International Financial Integration: Theory and Facts" World Bank Working Paper

Baldacci, E., L.D. Mello and G. Inchauste (2002). "Financial Crisis, Poverty and Income Distribution" IMF Working Paper, WP/02/04,

Berg, A. and C. Pattillo (1999a). "Are Currency Crises Predictable? A Test" IMF Staff Papers; 46(2), June, pp. 107-38.

Berg, A. and C. Pattillo (1999b). "Predicting Currency Crises: The Indicators Approach and an Alternative" Journal of International Money and Finance; 18(4), August, pp. 561-86.

Berg, A., E. Borenszstein and C. Pattilo (2004). "Assessing Early Warning Systems: How They Worked in Practice" IMF Working Paper, WP/04/52, March

Berg, A., E. Borensztein, G.M. Milesi-Ferretti and C. Pattillo (1999). "Anticipating Balance of Payments Crises: The Role of Early Warning Systems," IMF Occasional Paper 186.

Bhattacharyay, B. (2001). "Strengthening and Harmonization of MPIs for monitoring financial asset markets in Asia and Pacific", presented at the concluding workshop of Regional Technical Assistance 5869, Manila, Asian Development Bank, 16-18 May 2001.

Bhattacharyay, B. (2004). "A Quantitative Framework for Macroprudential/Financial Soundness Analysis for Monitoring Economic and Financial Vulnerability", Irving Fisher Committee (ifc) Bulletin, No. 19, November, 2004, Brussels.

Bhattacharyay, B., and G. Nerb (2002). "Leading Indicators for Monitoring the Stability of Asset and Financial Markets in the Asia and Pacific", Asia Pacific Development Journal, Vol. 9, No. 2, United Nations ESCAP, Bangkok, December.

Blaschke, W., T.J. Mathew, M. Giovanni and S.M.M. Peria (2001). "Stress testing of Financial Systems: An overview of issues, methodologies and FSAP experiences", IMF Working Paper 01/88, IMF, Washington, D. C.

Bordo, M., B, Eichengreen, D, Klingebiel and S.M.M. Peria (2001). "Is the Crisis Problem Growing More Severe?" Economic Policy 32.

Chen, S. and M. Ravallion (2001), "How Did the World's Poorest Fare in the 1990s?", Policy Research Paper no. 1620, Washington, D.C., World Bank.

Cihak, M. (2003) "Stress Testing: A Review of Concepts", paper written within the framework of the Czech National Bank Research Project No. B6/2003 and presented in a seminar at Czech National Bank, December 2003. 
Davis, E.P. (1999). "Financial data needs for macroprudential surveillance - What are the key indicators of risks to domestic financial stability?" Centre for Central Banking Studies, Bank of England.

Edison, H. (2000). "Do indicators of financial crises work? An evaluation of an early warning system." Board of Governors of the Federal Reserve System. International Finance Discussion Papers, 675.

Eichengreen, B., A. Rose and C. Wyplosz (1995). "Exchange Market Mayhem: The Antecedents and Aftermaths of Speculative Attacks", Economic Policy, 21, pp. 249-312.

Estanislao J.P., G.N. Manzano and G.O. Pasadilla (2000). "The Asian Financial Crisis: An East Asian Perspective," Asian-Pacific Economic Literature, May.

Evans, O., A. Leone, M. Gill and P. Hilbers (2000). "Macroprudential Indicators of Financial System Soundness", IMF Occasional Paper, 192.

Fratzscher. M. (2002). "On Currency Crisis and Contagion", Working Paper No. 139, European Central Bank, Frankfurt, April

Goldstein, M., G. Kaminsky and C. Reinhart (2000). Assessing Financial Vulnerability, An Early Warning System for Emerging Markets, Institute for International Economics, June.

International Monetary Fund (2001a). "Macroprudential Analysis: Selected Aspects Background Paper", June 7, IMF, Washington, D. C.

International Monetary Fund (2001b). "Financial Sector Assessment Program (FSAP): A Review: Lessons from the Pilot and Issues Going Forward, Available via the internet http:// www. Imf.org/np/fsap/2001/review.htm, IMF, Washington, D. C.

International Monetary Fund and the World Bank (2003). "Analytical Tools of FSAP", http://www.imf.org/exteranl/np/fsap/2003/022403a.pdf.

International Monetary Fund (2004). "Compilation Guide on Financial Soundness Indicators", IMF, Washington, D. C.,

Jones, T. M., P. Hilbers and L.G. Slack (2004). "Stress Testing Financial Systems: What to do When Governor Calls", IMF Working Paper, WP/04/127, Washington D.C., July 2004.

Kaminsky, G., S. Lizondo and C. Reinhart (1998). "Leading Indicators of Currency Crises", IMF Staff Papers, 45, No. 1, pp. 1-48.

Kaminsky, G. and C. Reinhart (1999). "The Twin Crises: The Causes of Banking and Balance-of-Payments Problems", American Economic Review; 89(3), pp. 473-500, June.

Kaminsky, G. and C. Reinhart, (2000). "On Crises, Contagion, and Confusion"; Journal of International Economics; 51(1), pp. 145-68, June.

Krugman, P. (1979). "A Model of Balance of Payments Crises". Journal of Money Credit and Banking, 11: 311-28. 
Nerb, G., C. Hott and André Kunkel (2007)."The accuracy of turning-point predictions with the Ifo Business Climate", in: Goldrian, G. (2007). "Handbook of survey-based business cycle analysis", Elgar, Cheltenham, 175-196.

Obstfeld, M. (1986). "Rational and Self-Fulfilling Balance-of-Payments Crises", The American Economic Review, Vol. 76, No. 1 (Mar., 1986), pp. 72-81

Prasad E., K. Rogoff, S.J. Wei and M.A. Kose (2003). "Effects of Financial Globalization on Developing Countries: Some Empirical Evidence", IMF, 17 March 2003.

Pesenti, P. and T. Cedric (2000). "The Economics of Currency Crises and Contagion: An Introduction". Federal Reserve Bank of New York Economic Policy Review, September, pp 3-16.

Salvatore, D. (1999). "Could the Financial Crisis in East Asia Have Been Predicted?" Journal of Policy Modeling 21, no. 3: 341-47.

Sundararajan, V. et al., 2002. "Financial Soundness Indicators: Analytical Aspects and Country Practices", IMF Occasional Paper No. 212.

United Nations Economic and Social Commission for Asia and the Pacific (UN ESCAP). (2000). Economic and Social Survey of Asia and the Pacific. New York. 


\section{Appendix: Technical Details / Sources for the Construction of the Indicators}

For each composite indicator, we list the following information:

Name and short description of the

included time series
Source (e.g. EcoWin shortcut) and mathematical compilation of the indicator
Range of the figures of the respective source

\section{VII.1.1 Composite Leading Indicator (CLI)}

1. Oil Price, rate of change (m-o-m)

2. US Leading Index, rate of change (m-o-m)

3. M2, growth (y-o-y)

4. Real Stock Price, rate of change (m-o-m)

5. Economic Climate for KAZ (Ifo World Economic Survey)

6. Industry, Manufacturing of Industrial Products, Expectations

7. Industry, Expectations for Demand for Finished Goods

8. Industry, Stock of Finished Goods, Expectations
EcoWin: ew:com20455, WTI Crude Oil, Spot, USD

EcoWin: ew:usa07011, Composite Leading Indicator, Amplitude Adjusted (that means our use of the HP-filter would not have been absolutely necessary)

EcoWin: ew:kzt12050

EcoWin: ew:kzt15501, divided by Kazakh CPI (from the Statistical Agency of Kazakhstan, SAK) to obtain real values

Ifo World Economic Survey

Source: SAK, Balanced Answers, Survey

Source: SAK, Balanced Answers, Survey

Source: SAK, Balanced Answers, Survey
M: Jan $46-$ Aug 08

M: Jan 55 Aug 08

M: Dec 93 July 08

D: June 00 Sept 08

Q: 99Q1 08Q3

Q: 04Q1 08Q1

Q: 04Q1 08Q1

Q: 04Q1 08Q1

(5. to 8. are quarterly data, which have to be disaggregated using ECOTRIM) 


\section{VII.1.2 Composite Coincident Indicator (CCI)}

1. Activity Index, Physical Volume Index

2. Real Wages; monthly average

3. Economically Active Population

4. Retail Sales, real
Source: SAK

Source: SAK

Source: SAK

Source: SAK
M: Jan $96-$ Oct

08

M: Jan $03-$

Sept 08

M: Jan 04 - Aug

08

M: Jan $00-$

Sept 08

\section{VII.1.3 Composite Financial Market Risk Indicator (CFMI)}

1. M2/Foreign International Reserves

2. Inverse of the Real Exchange Rate growth (y-o-y)

3. Real Rate of Interest: KAZ Treasury Bill Interest Rate Inflation

4. World Interest rate differential: KAZ Treasury Bill Rate of Interest - US Treasury Bill Rate of Interest)

5. Trade Deficit Ratio: GDP / Current Account Balance (both quarterly, data have to be disaggregated using ECOTRIM)
EcoWin: $M 2$ in $\mathrm{KZT}$ (ew:kzt12050) / [ Spot Rates in KZT/USD (ew:kzt19001) * Gross International Reserves (ew:kzt16105) ]

EcoWin: [ CPI US (ifs:s11163ba0zfm ) multiplied by Spot Rates in KZT/USD (ew:kzt19001) ] / CPI KAZ (SAK)

EcoWin: Treasury Bills Rate (ifs:s91660c00zfm) Inflation (ifs:s9166400xzfm)

EcoWin: KAZ Treasury Bills (ifs:s91660c00zfm) - US Treasury Bills, 91 days maturity (ew:usa71225)

EcoWin: [ Current Account Balance (ifs:s91678aldzfq)

* Spot Rates KZT/USD (ew:kzt19001) ] / GDP (ifs:s91699b00zfq)

multiplied by -1
M: Dec 93 - July 08

D: Jan 95 - Sept 08

M: Dec 98 - June 08

M: Dec 98 - June 08

Q: 95Q1 - 08Q1 


\section{VII.1.4 Composite Banking Stress Indicator (CBI)}

1. Long term Foreign Liabilities of Banks / Foreign Assets

2. Ratio of Bank Loans to Trade, Construction and Industry over Total Loans

3. Total Bank Loans growth (y-o-y)

4. Interest Rate Companies Paying to Banks - Inflation

5. Profitability of Banks : Interest Rate Companies Paying to Banks Interest Rate on Treasury Bill

6. Total Bank Loans / GDP

7. Liquidity Risk: M2/Total Loans

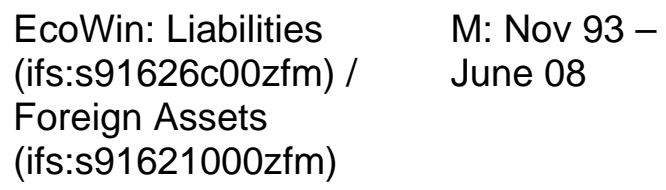

EcoWin: Liabilities (ifs:s91626c00zfm) /

M: Nov $93-$ Foreign Assets (ifs:s91621000zfm)

Source: SAK

Q: 04Q1 - 08Q1

Source: SAK

Q: 96Q1 - 08Q1

Source: SAK

Q: 97Q1 - 08Q2

Source: SAK, Treasury

Bills Rates from

EcoWin

(ifs:s91660c00zfm)

Source: SAK

Q: 96Q1 - 08Q1

Source: SAK, M2 from

EcoWin (ew:kzt12050)

Q: 96Q1 - 08Q1

\section{VII.1.5 International Economic Environment Indicator (IEEK)}

Ifo World Economic Survey, trade weighted*) external economic climate*^) for Kazakhstan

*) Economic climate is a weighted average of respective data for Italy (weight: 16), Switzerland (16), China P.R. (12), Russia (10), France (8), Netherlands (5), Iran (5), UK (3), Ukraine (2), Israel (2), Spain (2), Romania (2), Rest of world (17).

In the period 1993 to 1st quarter 1999, Iran, Ukraine, Israel and Romania are not included.

**) Arithmetic mean of judgment of present and expected economic situation.

As the IEEK is only available on a quarterly basis, it has been treated with Ecotrim. 


\section{CESifo Working Paper Series}

for full list see www.cesifo-group.org/wp

(address: Poschingerstr. 5, 81679 Munich, Germany, office@cesifo.de)

2773 Erdal Yalcin, Uncertain Productivity Growth and the Choice between FDI and Export, August 2009

2774 Klaus Abberger, Wolfgang Nierhaus and Shynar Shaikh, Findings of the Signal Approach for Financial Monitoring in Kazakhstan, September 2009

2775 Sascha O. Becker, Francesco Cinnirella and Ludger Woessmann, The Trade-off between Fertility and Education: Evidence from before the Demographic Transition, September 2009

2776 Thomas Aronsson and Erkki Koskela, Optimal Income Taxation, Outsourcing and Policy Cooperation in a Dynamic Economy, September 2009

2777 Joel Slemrod, Old George Orwell Got it Backward: Some Thoughts on Behavioral Tax Economics, September 2009

2778 Cagri Seda Kumru and Athanasios C. Thanopoulos, Social Security Reform and Temptation, September 2009

2779 Alessandro Bucciol and Roel M. W. J. Beetsma, Inter- and Intra-generational Consequences of Pension Buffer Policy under Demographic, Financial and Economic Shocks, September 2009

2780 Eduardo Strube and Marcelo Resende, Complementarity of Innovation Policies in the Brazilian Industry: An Econometric Study, September 2009

2781 Henry Tulkens and Vincent van Steenberghe, "Mitigation, Adaptation, Suffering": In Search of the Right Mix in the Face of Climate Change, September 2009

2782 Maria L. Loureiro, Anna Sanz-de-Galdeano and Daniela Vuri, Smoking Habits: Like Father, Like Son, Like Mother, Like Daughter, September 2009

2783 Momi Dahan, Tehila Kogut and Moshe Shalem, Do Economic Policymakers Practice what they Preach? The Case of Pension Decisions, September 2009

2784 Eytan Sheshinski, Uncertain Longevity and Investment in Education, September 2009

2785 Nannette Lindenberg and Frank Westermann, How Strong is the Case for Dollarization in Costa Rica? A Note on the Business Cycle Comovements with the United States, September 2009

2786 Leif Danziger, Noncompliance and the Effects of the Minimum Wage on Hours and Welfare in Competitive Labor Markets, September 2009 
2787 Gerlinde Fellner, Rupert Sausgruber and Christian Traxler, Testing Enforcement Strategies in the Field: Legal Threat, Moral Appeal and Social Information, September 2009

2788 Gabriel J. Felbermayr, Mario Larch and Wolfgang Lechthaler, Unemployment in an Interdependent World, September 2009

2789 Sebastian G. Kessing, Federalism and Accountability with Distorted Election Choices, September 2009

2790 Daniel Gros, Global Welfare Implications of Carbon Border Taxes, September 2009

2791 Louis N. Christofides, Michael Hoy and Ling Yang, The Gender Imbalance in Participation in Canadian Universities (1977-2005), September 2009

2792 Jan K. Brueckner and Robert W. Helsley, Sprawl and Blight, September 2009

2793 Vidar Christiansen and Stephen Smith, Externality-correcting Taxes and Regulation, September 2009

2794 John Beirne, Guglielmo Maria Caporale, Marianne Schulze-Ghattas and Nicola Spagnolo, Global and Regional Spillovers in Emerging Stock Markets: A Multivariate GARCH-in-mean Analysis, September 2009

2795 Rüdiger Pethig and Frieder Kolleß, Asymmetric Capital-Tax Competition, Unemployment and Losses from Capital Market Integration, September 2009

2796 Ngo Van Long, Horst Raff and Frank Stähler, Innovation and Trade with Heterogeneous Firms, September 2009

2797 Margit Osterloh and Bruno S. Frey, Research Governance in Academia: Are there Alternatives to Academic Rankings?, September 2009

2798 Thiess Buettner and Clemens Fuest, The Role of the Corporate Income Tax as an Automatic Stabilizer, September 2009

2799 Annette Alstadsæter, Measuring the Consumption Value of Higher Education, September 2009

2800 Peter Friedrich, Chang Woon Nam and Janno Reiljan, Local Fiscal Equalization in Estonia: Is a Reform Necessary?, September 2009

2801 Evžen Kočenda and Jan Hanousek, State Ownership and Control in the Czech Republic, September 2009

2802 Michael Stimmelmayr, Wage Inequality in Germany: Disentangling Demand and Supply Effects, September 2009

2803 Biswa N. Bhattacharyay, Towards a Macroprudential Surveillance and Remedial Policy Formulation System for Monitoring Financial Crisis, September 2009 
2804 Margarita Katsimi, Sarantis Kalyvitis and Thomas Moutos, "Unwarranted" Wage Changes and the Return on Capital, September 2009

2805 Christian Lessmann and Gunther Markwardt, Aid, Growth and Devolution, September 2009

2806 Bas Jacobs and Dirk Schindler, On the Desirability of Taxing Capital Income to Reduce Moral Hazard in Social Insurance, September 2009

2807 Hans Gersbach and Noemi Hummel, Climate Policy and Development, September 2009

2808 David E. Wildasin, Fiscal Competition for Imperfectly-Mobile Labor and Capital: A Comparative Dynamic Analysis, September 2009

2809 Johan Eyckmans and Cathrine Hagem, The European Union's Potential for Strategic Emissions Trading through Minimal Permit Sale Contracts, September 2009

2810 Ruediger Bachmann and Christian Bayer, The Cross-section of Firms over the Business Cycle: New Facts and a DSGE Exploration, October 2009

2811 Slobodan Djajić and Michael S. Michael, Temporary Migration Policies and Welfare of the Host and Source Countries: A Game-Theoretic Approach, October 2009

2812 Devis Geron, Social Security Incidence under Uncertainty Assessing Italian Reforms, October 2009

2813 Max-Stephan Schulze and Nikolaus Wolf, Economic Nationalism and Economic Integration: The Austro-Hungarian Empire in the Late Nineteenth Century, October 2009

2814 Emilia Simeonova, Out of Sight, Out of Mind? The Impact of Natural Disasters on Pregnancy Outcomes, October 2009

2815 Dan Kovenock and Brian Roberson, Non-Partisan 'Get-Out-the-Vote' Efforts and Policy Outcomes, October 2009

2816 Sascha O. Becker, Erik Hornung and Ludger Woessmann, Catch Me If You Can: Education and Catch-up in the Industrial Revolution, October 2009

2817 Horst Raff and Nicolas Schmitt, Imports, Pass-Through, and the Structure of Retail Markets, October 2009

2818 Paul De Grauwe and Daniel Gros, A New Two-Pillar Strategy for the ECB, October 2009

2819 Guglielmo Maria Caporale, Thouraya Hadj Amor and Christophe Rault, International Financial Integration and Real Exchange Rate Long-Run Dynamics in Emerging Countries: Some Panel Evidence, October 2009 
2820 Saša Žiković and Randall K. Filer, Hybrid Historical Simulation VaR and ES: Performance in Developed and Emerging Markets, October 2009

2821 Panu Poutvaara and Andreas Wagener, The Political Economy of Conscription, October 2009

2822 Steinar Holden and Åsa Rosén, Discrimination and Employment Protection, October 2009

2823 David G. Mayes, Banking Crisis Resolution Policy - Lessons from Recent Experience Which elements are needed for robust and efficient crisis resolution?, October 2009

2824 Christoph A. Schaltegger, Frank Somogyi and Jan-Egbert Sturm, Tax Competition and Income Sorting: Evidence from the Zurich Metropolitan Area, October 2009

2825 Natasa Bilkic, Thomas Gries and Margarethe Pilichowski, Stay in School or Start Working? - The Human Capital Investment Decision under Uncertainty and Irreversibility, October 2009

2826 Hartmut Egger and Udo Kreickemeier, Worker-Specific Effects of Globalisation, October 2009

2827 Alexander Fink and Thomas Stratmann, Institutionalized Bailouts and Fiscal Policy: The Consequences of Soft Budget Constraints, October 2009

2828 Wolfgang Ochel and Anja Rohwer, Reduction of Employment Protection in Europe: A Comparative Fuzzy-Set Analysis, October 2009

2829 Rainald Borck and Martin Wimbersky, Political Economics of Higher Education Finance, October 2009

2830 Torfinn Harding and Frederick van der Ploeg, Is Norway's Bird-in-Hand Stabilization Fund Prudent Enough? Fiscal Reactions to Hydrocarbon Windfalls and Graying Populations, October 2009

2831 Klaus Wälde, Production Technologies in Stochastic Continuous Time Models, October 2009

2832 Biswa Bhattacharyay, Dennis Dlugosch, Benedikt Kolb, Kajal Lahiri, Irshat Mukhametov and Gernot Nerb, Early Warning System for Economic and Financial Risks in Kazakhstan, October 2009 